Max-Planck-Institut für demografische Forschung

Max Planck Institute for Demographic Research

Konrad-Zuse-Strasse 1 - D-18057 Rostock · GERMANY

Tel +49 (0) 3812081 - 0; Fax +49 (0) 3812081 - 202;

http://www.demogr.mpg.de

MPIDR WORKING PAPER WP 2005-022

AUGUST 2005

\title{
Economic progress as cancer risk factor \\ II. Why is overall cancer risk higher in more developed countries?
}

Svetlana V. Ukraintseva (ukraintseva@cds.duke.edu)

Anatoly I. Yashin (yashin@cds.duke.edu)

(C) Copyright is held by the authors.

Working papers of the Max Planck Institute for Demographic Research receive only limited review. Views or opinions expressed in working papers are attributable to the authors and do not necessarily reflect those of the Institute. 


\title{
Economic Progress as Cancer Risk Factor II. Why is Overall Cancer Risk Higher in More Developed Countries?
}

\author{
${ }^{\star}$ Svetlana V. Ukraintseva ${ }^{1}$ and Anatoly I. Yashin ${ }^{1,2}$ \\ ${ }^{1}$ Duke University Center for Demographic Studies, Durham, USA \\ ${ }^{2}$ Max Planck Institute for Demographic Research, Rostock, Germany \\ E-mails: ukraintseva@cds.duke.edu; yashin@cds.duke.edu; \\ *Corresponding author: E-mail: ukraintseva@cds.duke.edu; Tel: +1 (919) 668-2712
}

\begin{abstract}
Analysis of data on cancer incidence rates in different countries at different time periods revealed positive association between overall cancer risk and economic progress. Typical explanations of this phenomenon involve improved cancer diagnostics and elevated exposure to carcinogens in industrial countries. Here we provide evidence from human and experimental animal studies suggesting that some other factors associated with high economic development and Western life style may primarily increase the proportion of susceptible to cancer individuals in a population and thus contribute to elevated cancer risks in industrial countries. These factors include (but not limited to): (i) better medical and living conditions that "relax" environmental selection and increase share of individuals prone to chronic inflammation; (ii) several medicines and foods that are not carcinogenic themselves but affect the metabolism of established carcinogens; (iii) nutrition enriched with growth factors; (iv) delayed childbirth. The latter two factors may favor an increase in both cancer incidence rate and longevity in a population. This implies the presence of a trade-off between cancer and aging: factors that postpone aging may simultaneously enhance organism's susceptibility to several cancers.

Key words: cancer risk, individual susceptibility, economic progress, aging
\end{abstract}

\section{Table of contents}

\section{Introduction}

1.1 Why focus on overall cancer risk?

1.2 Why is the overall cancer risk higher in more developed countries?

\section{Improved cancer diagnostics}

2.1 Improved diagnostics does not fully explain rising cancer risks

2.2 Improved identification of tumors

2. 3 Effects of early detection

2. 4 Sex differences in time trends for the same cancer site

\section{Elevated exposure to carcinogens}

3.1 Is the increase in cancer risks due to increased carcinogenic load?

3.2 Infections and cancer

3.3 Many of today's carcinogens existed and were even more prevalent in the past

3.4 Increased cancer rates at a time of decreased exposure to tobacco smoking

3.5 Why has the overall cancer risk increased in the former East Germany and the Soviet Union? 


\section{Increased proportion of susceptible to cancer individuals}

4.1 How does economic progress increase susceptibility to cancer?

4.2 How improvements in health standards increase the proportion of individuals susceptible to cancer

4.3 How the western life-style increases vulnerability to cancer

4. 4 Factors of economic progress that increase both longevity and vulnerability to cancer

\section{Concluding remarks}

\section{Acknowledgements}

\section{References}

\section{Introduction}

\subsection{Why focus on Overall Cancer Risk?}

Cancer is the generic term for more than 100 diseases, each characterized by a specific etiology, pathogenesis, and tissue localization. The development of cancer has multiple causes, including genetic predisposition, infectious agents, and exposure to chemical or physical carcinogens. Can we discuss risk factors that are common for a set of different diseases? As far as cancer is concerned, this is justified because most cancers share common key features. They include uncontrolled abnormal growth of cells, their potential immortality, de-differentiation, and capacity for invasion and metastasis (Abelev 1997, Bast et al. 2000, Hanahan and Weinberg 2000). These common features suggest that there exist common risk factors for different cancers. For instance, chronic inflammation is one such factor because it promotes almost all cancer features described above (Coussens and Werb 2002). If some factors linked to economic progress favor an increase in the proportion of people with chronic inflammation, these factors may simultaneously increase cancer risk in a given population. On the other hand, if there is successful treatment for an inflammatory disease, then the risks of relevant cancers may decline.

\subsection{Why is the Overall Cancer Risk Higher in More Developed Countries?}

Our analysis of epidemiological data on cancer incidence rates in different countries and at different time periods revealed a positive association between the level of economic development and the overall cancer risk (see paper I. Puzzling Facts of Cancer Epidemiology). Typical explanations focus on improved cancer diagnostics and elevated exposure to carcinogens.

Here, we provide compelling evidence from human and animal studies suggesting that several other factors associated with high economic development and a Western life-style make substantial contributions to rising cancer risks. These factors influence the proportion of individuals vulnerable to cancer rather than the carcinogenic exposure in a population. 
They include improvements in medical care and living conditions, which "relax" environmental selection and increase the share of people prone to chronic inflammation (the latter is an important cancer promoting factor). Several factors specific to a Western life-style (e.g., new foods and medicines) may enhance individual susceptibility to cancer. Not essentially carcinogenic themselves, these affect the metabolism of established carcinogens and thus have the potential to favor cancer risks. In addition, there are factors that influence both an organism's aging and vulnerability to cancer. For example, food enriched with growth factors or delayed childbirth may affect some characteristics of aging and development (such as the duration of the growth period, the ages of menarche and menopause, parental age, height, and weight), so that it would favor a postponement of aging manifestation and an increase in longevity. These same factors may also enhance individual vulnerability to cancer (to be discussed). This implies the presence of a trade-off between cancer and aging: Factors that postpone aging may simultaneously elevate cancer incidence rate in a population.

\section{Improved Cancer Diagnostics}

\subsection{Improved Diagnostics Does not Fully Explain Rising Cancer Risks}

Improved cancer diagnostics allows for the earlier detection of tumors and/or the better identification of the disease. Both factors can contribute to an increase in the cancer incidence rate and are often considered to be major causes of such a rise. However, this assumption, while valid for some cancers (e.g., of the prostate), does not seem to have a solid empirical basis for many other cancer sites. Here, we examine the effects of improved cancer diagnostics on cancer incidence rates, taking into account some accompanying factors, such as the spontaneous regression of tumors, survival of cancer patients and sex differences, to show that improved diagnostics does not fully explain the rise in cancer risks.

\subsection{Improved Identification of Tumors}

More efficient methods of cancer diagnostics allow for the identification of tumors that would not be detected by current methods. The former increases the total number of cancers detected in individuals of selected age groups. It is reasonable to assume that for each age category the number of additional tumors identified with improved diagnostics is proportional to the number of tumors detected by current methods. The new cancer incidence rate would then increase faster with age than the old one. This prediction corresponds to available data, suggesting that the 
improved identification of tumors contributes to a rise in cancer incidence rates in developed countries (Figure1).

Figure 1 about here

Some clinical studies provide supporting evidence for this conclusion. In a study of histologically detected adenocarcinomas of the prostate involving 179,298 men in the Netherlands, Giard and co-authors (1998) explained most of the increase in the incidence rate of this cancer between 1990 and 1996 by more intensive diagnostics with prostate-specific antigen (PSA) and transrectal ultrasonography. Some other studies, however, suggested that the impact of improved diagnostics (particularly routine PSA testing) on the rate of incidental prostate cancer is less substantial (Zigeuner et al. 2003). Improved diagnostics may explain at least part of the steep increase (by almost 200 percent) in the incidence rate of prostate cancer that occurred over the last 50 years (Ries et al. 2001).

It is unlikely, however, that the improved identification of tumors is responsible for the enormous increases in the risks of many other cancers such as melanoma of the skin, lung cancer, myeloma and non-Hodgkin lymphoma. Together, these cancers contributed to a large extent to the growth in the overall cancer risk during the second half of the last century. Their rates in the USA rose by about 200- 500 percent during this period (Ries et al. 2001). There is no convincing evidence that only improved diagnostics accounts for such an enormous elevation of the rates. Furthermore, some studies show that there has been no radical improvement in the detection of lung cancer, melanoma of skin, and myeloma (sites that have the highest increase in the rate) (De Rooij et al. 1996, Hirsch et al. 2002).

Female breast cancer rates have risen less rapidly but still substantially (about 70 percent) during the last 50 years in the USA (Ries et al. 2001). New methods of mass screening using mammography added only about 1 percent of new cancer cases to those detected by ordinary physical examination (Morimoto et al. 1994). The rate of female breast cancer drastically increased 1960-62 and 1988-92 in Moscow (Russia) (see Chapter 2.1). This rise took place without a population-wide application of new cancer detection methods, and hence requires a different explanation.

For some cancer sites, the incidence rates are higher in less developed countries. Examples include cervix, esophagus, stomach, and liver cancers. Their elevated rates naturally can not be attributed to improved cancer diagnostics in less developed countries. Cervical and stomach cancers have been showing a decline in the risks by about 80 percent in the USA during 
the last 50 years (Ries et al. 2001). Again, the fall in incidence rates could not have occurred as a result of improved diagnostics of these cancers. If so, then why should one a priori accept the pivotal role of improved diagnostics in the increased risks of other cancers?

We conclude that improved identification of tumors partly contributes to the contemporary increase in the overall cancer risk in developed countries. However, it is unlikely to be the only factor responsible for such an increase.

\section{3 Effects of Early Detection}

Early detection alone. Consider a hypothetical situation: New methods of cancer diagnostics detect about the same number of cancer cases as the older technology, but at earlier ages. What would the effect be on cancer incidence rate curves? Let us ignore the possibility of detecting tumors that regressed spontaneously thereafter, and would therefore not have been observed with the older technology. Let us also ignore the effect of dying from competing causes. In this case, one may expect that the new age-specific cancer incidence rate can be produced from the old one by a parallel shift of the former incidence rate to the left. Figure 1 above shows that the change in cancer risks over time does not follow this pattern. We can see from this figure that the new incidence rate increases faster with age than the old one.

Decline in the tumor growth rate with age. The rate of tumor growth commonly declines at old ages in cancer patients (Peer et al. 1993, Semiglazov et al. 1989, Kozma 1998, Maehara et al. 1996). Possible reasons are discussed by Ukraintseva and Yashin (2003). With this decline, improved diagnostics will detect tumors with longer durations of growth at older ages than at younger ages. This may contribute to the higher incidence rate at older ages by shifting the entire incidence rate curve to the left.

Spontaneous tumor regression. The earlier detection may include tumors that will later regress spontaneously. Here, the total of newly detected tumors may be higher than observed with former methods of diagnostics. To produce a faster increase in the incidence rate, the new methods of cancer diagnostics must detect more cases of spontaneously regressed tumors in the elderly than in youth and adulthood. This scenario, however, does not seem realistic because the majority of spontaneously regressed tumors arise in infancy. Infant neuroblastoma is an example of a cancer with a high propensity to spontaneous regression (Ries et al. 1999).

Survival of cancer patients. The most important effect of early tumor detection is, obviously, the better survival of cancer patients. This is because earlier detected tumors have a higher chance of being curable, and because early detection may reveal more tumors with a 
propensity to spontaneous regression. Both factors increase the share of patients surviving cancer. If earlier detection is also responsible for a rise in the cancer incidence rate, then we can expect a higher survival rate of cancer patients in countries with higher incidence rates (Figure 2).

Figure 2 is about here

We see from this figure that there is no clear relationship between cancer incidence and survival rates in European countries. For instance, the lowest incidence rates are in the UK and in Sweden, which are countries manifesting the worst and the best survival from cancer, respectively. The lack of a positive correlation between incidence and survival suggests that more factors in addition to improved diagnostics are involved in creating higher overall cancer risks in more developed countries.

\section{4 Sex Differences in Time Trends for the Same Cancer Site}

Lungs are one the most prevalent cancer sites in both males and females. Lung cancer substantially contributes to the overall cancer risk. A comparison between male and female trends in the incidence rate for this cancer suggests that improved cancer diagnostics accounts for only small portions of the rise in lung cancer risk. Figure $3(1,2)$ shows age-patterns of lung cancer incidence rates in different years, and the ratio of the rates 1960-1962 to 1988-1992 in the USA, by sex.

Figure $3(1,2)$ about here

As can be seen from this figure, the relative increase in lung cancer risks between 196062 and 1988-92 was much higher for females than for males, particularly at ages 50-80. This difference cannot be explained by improved lung cancer diagnostics, since the latter would have produced similar relative changes for both sexes.

In summary, the available data do not provide the grounds for explaining the increase in cancer risk solely by the improved quality of cancer diagnostics in more developed countries. Although better diagnostics may contribute to an increase in incidence rates for certain cancers (e.g., of the prostate), it can not explain multifold increases in the risk of cancer in other sites that are largely responsible for the increase in the overall rate in developed countries. Other factors, such as elevated exposure to environmental carcinogens, changes in the frailty distribution or 
increasing individual susceptibility to cancer in modern human populations, may be more important. We discuss the role of these factors in the sections below.

\section{Elevated Exposures to Carcinogens}

\subsection{Is the Increase in Cancer Risks due to Increased Carcinogenic Load?}

Another popular explanation of the higher overall cancer risk in more developed regions is the higher exposure of individuals to environmental carcinogens (e.g., linked to industrial pollution). How strong is the basis for such an explanation? In this section we show that the evidence of excess in the carcinogenic burden assumed to exist in more developed countries is not sufficiently substantial to explain the enormous differences in cancer risks between these and less developed countries. The change in the spectrum of prevalent carcinogens (sometimes resulting in decreased total carcinogenic exposure) may be a more important factor.

\subsection{Infections and Cancer}

Numerous studies stressed the important role of infection in the etiology of human cancers. The Helicobacter pylori, and Hepatitis and Papilloma viruses are examples of relevant infectious agents (IARC Monographs 1994a, b, 1995a; EstEve et al. 1993, Parsonnet 1999, Brenner 2000). Helicobacter pylori are bacteria living in the pylorus. In some circumstances (e.g., lowered acidity), they move up into the stomach. The products of their metabolism contribute to an increase in the risk of stomach cancer (IARC Monographs 1994b). Infection with the Hepatitis B virus elevates the risk of liver cancer (IARC Monographs 1994a). The Papilloma virus was shown to elevate the risk of cervical cancer (IARC Monographs 1995b). The wide use of antibiotics, antiviral treatment, and vaccinations as well as higher levels of hygiene has lowered the exposure of human organisms to many kinds of infections in more developed countries. This partly explains the lower risks of infection-related cancers (e.g., of the stomach, cervix, and liver) in these countries compared to less developed ones. That is, exposure to some infectionrelated carcinogens has been decreasing in parallel with economic progress.

\subsection{Many of Today's Carcinogens Existed and Were Even More Prevalent in the Past}

The IARC monographs on the Evaluation of Carcinogenic Risks to Humans, published between 1972 and 2001, describe the results of studies on 869 agents and mixtures found in the modern environment. Only 10 percent $(n=87)$ were established as clearly carcinogenic to humans (IARC 
Monographs 1972-2001). Furthermore, most of these carcinogens not only existed in the past, but were equally, and sometimes more, prevalent.

For example, 25 manufacturers that use or produce various carcinogenic substances were listed in the reports on industrial exposure of humans to carcinogens. About half of the carcinogens existed in the beginning of the last century. Unhealthy working conditions and limited knowledge about cancer risk factors make it very likely that the people working at the manufacturing plants were exposed to carcinogens in the past to a higher extent than their counterparts of today. Industries associated with coal, soot, tar, and sawdust; shoe manufacturing and repairing; furniture and cabinet making; the rubber industry; and iron and steel production are examples (IARC Monographs 1987, 1995b).

Practically every individual was permanently exposed in the past to some established carcinogens (e.g., coal, tar and soot) during normal home life. These common daily exposures have virtually ceased today.

\subsection{Increased Cancer Rates at a Time of Decreased Exposure to Tobacco Smoking}

Tobacco smoking is an established risk factor for many cancers. It is widely accepted that smoking today is responsible for the high incidence rate of lung cancer in males as well as for the increase in the incidence rate over time in females (Tominaga 1999). Let us consider the connection between smoking and trends in lung cancer risks in greater detail.

Females are more vulnerable to smoking. As shown in Figure 3 above, lung cancer rates increased between 1960-62 and 1988-92 much more rapidly for females than for males, particularly at ages 50-80. The sex difference can be explained by higher susceptibility of the female organism to harmful tobacco products rather than by higher exposure of women to smoking compared to men.

Individual vulnerability to tobacco smoking depends on the presence of certain metabolizing enzymes (e.g., cytochromes P450), which convert nicotine and some other tobacco products into active carcinogens (Napalkov et al. 1987, Buters et al. 1999, Gonzalez 2000). For instance, the higher expression of the CYP1A1, a nicotine metabolizing enzyme, is shown to be associated with a higher risk of lung cancer among smokers. However, the expression of this enzyme is commonly higher in smoking women than in smoking men (Gonzalez 2000). That is, the female enzymatic system is likely to be more susceptible to nicotine than that of males. A large case-control study by the American Health Foundation confirmed the higher susceptibility to tobacco carcinogens in U.S. women (Zang and Wynder 1996). At the same level of tobacco 
exposure, the odd ratios were 1.2-fold to 1.7-fold higher in women than in men for all three of the major histological types of lung cancer. This suggests that in a hypothetical case of the same increase in the proportion of smoking individuals among females and males, female cancer incidence rates would increase more rapidly over time. Has the proportion of smoking individuals increased over time, however?

The share of smoking individuals has been declining since the 1960s. In 1955, nearly 60 percent of white men in the USA were smokers. This proportion decreased through the 1960s to 50 percent. By 1974, male smoking dropped to less than 42 percent and this trend continued over the following decades. The data indicate that in 1994, only 27 percent of white men were smokers (Health US 2001). The proportion of smoking men in the USA thus decreased more than two-fold during the second half of the last century.

The proportion of smoking white females in the USA did not show such a steep decline over the same period. It increased from about 28 percent of white females in the 1950s to 34 percent in 1965, followed by a decrease to 32 and 24 percent in 1974 and 1994, respectively.

Thus, the share of smoking individuals declined in the USA both in males and females. Today, the share is similar for the two sexes. The recent deceleration and even decline in male lung cancer incidence and mortality rates (Health US 2001, Cole et al. 1996, Ries et al. 2001) may be a reflection of the success of tobacco control efforts among men over the past decades. Contrarily, the continuing increase in female lung cancer risks cannot be explained by stronger female smoking habits because the proportion of smoking women has declined in the USA since 1965. By 1994 the number of women smokers has been continuously declining for almost 30 years. One may suggest that the increase in female lung cancer today is a reflection of the past increase in the proportion of female smokers of almost 40 years ago. Similarly, one may assume that the decline in male lung cancer risks, first observed in the 1990s, directly reflects the decrease in the proportion of male smokers, which first begun more than 30 years before the decline in cancer rates. Some studies of changes in the carcinogenic risks of tobacco smoking after smoking cessation support this possibility (Ebbert et al. 2003). However, other data suggest that the risk of lung cancer begins to decline shortly after stopping smoking, and that the odds ratio falls two or three-fold (depending on the country and histologic type of lung cancer) by 15 years after the cessation of smoking (Khuder et al. 2001, Wakai et al. 2001).

These facts indicate the existence of other mechanisms (in addition to smoking) that contribute to the increase in lung cancer risks in modern populations. The elevated proportion of individuals susceptible to cancer in developed countries (discussed below) may play a substantial 
role in such a mechanism. This suggestion does not exclude smoking - an established carcinogen that has been confirmed in many studies. However, the fact that smoking elevates cancer risks does not mean that any observed increase in cancer risks is due solely to smoking.

\subsection{Why Has the Overall Cancer Risk Increased in the Former East Germany and the Soviet Union?}

Figure 4 shows age-specific cancer incidence rates in East and West Germany before reunification, by sex.

Fig. 4 about here

We see from this figure that the cancer incidence rates were higher in West Germany (an economically more developed region) than in East Germany (an economically less developed region) before reunification, both for males and females. The former East Germany had a high density of industrial plants and a high level of environmental pollution. After reunification, many industrial enterprises were closed or equipped with new, environment friendly technology. As a result, the level of industrial pollution declined substantially. Paradoxically, the overall cancer risk in the former East Germany increased during that time. A similar trend was observed in Russia. After the collapse of the Soviet Union, many industrial plants were closed, too, leading to a lowering of environmental pollution (Health in Russia 2000). In consequence, the ecological situation in the country improved, but the overall cancer risk increased nevertheless (Figurer 5(1)).

Fig. 5(1) about here

The figure shows that a steady increase in cancer incidence rates took place 1980-1999 in Russia, with the collapse of the Soviet Union in 1991 having had no noticeable effects.

The trends in cancer incidence rates in Russia and East Germany therefore seem not to be a concomitant of declining industrial pollution. A similar conclusion applies to smoking. The proportion of smoking males has remained almost constant (about 70 percent) in Moscow for many decades (McKee et al. 1998), while exposure to carcinogens related to tobacco smoking has decreased. This is because modern tobacco products have a significantly lower content of nicotine and tar than 50 years ago. Surprisingly, under these more favorable conditions, the male 
lung cancer incidence rate in Moscow increased rapidly until the 1990s, and began its deceleration only in the last decade of the century. The rate is still much higher today than in the past. Other smoking-related cancers (e.g., of the esophagus) have not shown favorable trends in Russia at all (Figure 5(2)).

Fig. 5(2) about here

Thus, an increase in the cancer incidence rate in East Germany and Russia has been observed despite decreased exposure to some established environmental carcinogens. This paradoxical behavior of cancer rates is possibly due to the following reasons:

(1) The latent periods for lung and some other cancers are much longer than assumed.

(2) Exposure to new carcinogens, or to those that were less prevalent in the past, has increased.

(3) Individual susceptibility to carcinogens, including those existing in the environment for a long time, has increased.

The first explanation does not have strong empirical support. The second seems realistic.

It implies that economic progress is accompanied by a change in exposure structure to carcinogens rather than a simple increase in carcinogenic load (e.g., exposure to soot at home has been replaced by the exposure to pollution from car exhausts). The change in the spectrum of prevalent carcinogens elevates cancer risks even without an increase in total carcinogenic burden. This is because long-term (multigenerational) exposure of a population to a particular carcinogen favors the survival of more resistant individuals (e.g., smoking men with a lowered expression of the CYP1A1, a nicotine-metabolizing enzyme). When a new carcinogen appears, it takes time for the population to adapt to it. During this time, cancer risk is elevated, and after the adaptation declines. The third reason will be discussed in detail in the next section.

\section{Increased Proportion of Individuals Susceptible to Cancer}

\subsection{How Does Economic Progress Increase Susceptibility to Cancer?}

Improved diagnostics and increased carcinogenic burden do not explain in full the association between the overall cancer risk and economic progress. Is this increase partly due to a higher proportion of individuals who are more susceptible to cancer in more developed countries?

First, let us address how increased susceptibility to a disease arises, using a simple example of allergy. Similar to cancer, the risk of allergic diseases (e.g., asthma and atopic dermatitis) drastically increased during the second half of the last century. It is also higher in 
more developed countries compared with less developed ones, even after adjustment for differences in diagnostic criteria (Trepka et al. 1996, Ukraintseva 1998). However, the majority of factors that directly induce allergic reaction (e.g., eggs, milk, pollen, wood or home dust) are natural and have been present in the human environment since thousands of years. These factors are not an exclusive feature of the more developed countries. Almost all people (in both more and less developed countries) are exposed to these natural substances, mostly without harm. Some individuals, however, react pathologically. This means that natural substances themselves do not cause the disease. Increased vulnerability of an organism to a normal environment is the true cause, possibly because its immunity is affected from factors associated with economic progress and a Western life-style.

Concerning vulnerability to cancer and respective morbid risks, we emphasize several groups of such factors:

(1) Improvements in medical care, hygiene, and living conditions that "relax" environmental selection and favor an increase in the proportion of individuals prone to chronic inflammation (the latter promotes cancer; Pozharisski et al. 1979,

Coussens and Werb 2002).

(2) Some nutritional products and medicines (of those prevalent in developed countries) that increase the vulnerability to cancer by affecting the metabolism of established carcinogens or favoring the chronic inflammation.

(3) Some factors attributed to the Western life-style (such as a higher parental age or food enriched with growth factors) that influence the parameters of individual aging and vulnerability to cancer in a way that increases both longevity and cancer risks in the populations of developed countries.

\subsection{How Improvements in Health standards Increase the Proportion of Individuals Susceptible to Cancer}

The higher the economic development of a country, the better the living standard and the quality of medical help in that country. These improvements lead to a "relaxation" of environmental selection and increase the proportion of individuals with various genetic and immune disorders in a population (Vogel and Motulsky, 1997; Ukraintseva, 1998). Improved medical and living conditions favor the survival of frail individuals, who are biologically more vulnerable to disease and would have died in the past. Besides, the immune system is not sufficiently trained under the improved conditions, and this also promotes rising vulnerability during an individual's life. The increase in the proportion of vulnerable individuals at young, adult, and old ages contributes to 
the higher risks of common diseases, including cancer, in developed countries. Below, we explore this possibility.

Improved survival during childhood. The decline in infant and childhood mortality was especially pronounced between the beginning of the last century and the 1980s. Today, survival during childhood is very close to the natural limit of 100 percent in developed countries. For instance, the infant mortality rate in the United States was about 3 percent of live births in 1950, around 1.3 percent in 1980, and about 0.7 percent in 1997 (Health US 2001). Most newborns in developed countries now reach the reproductive age. This radical improvement in survival is largely due to a decline in mortality from infectious disease, particularly from severe respiratory and intestinal infections. Contrarily, until recently, childhood mortality (up to 5 years) was nearly 20 percent in some regions of the least developed countries, such as India. This indicates that the pressure of environmental selection is much higher in the least developed countries than in the most developed ones. However, improved survival in more developed countries has its shadow side. Because almost all children (including those with immunity defects) survive, the proportion of children that are internally more susceptible to diseases is higher in more developed countries. This explains in part the paradox divergence between lower mortality from all causes and higher morbidity of various immune disorders (e.g., asthma, allergy, and chronic tonsillitis) in the children of the developed countries as compared to the less developed ones (Ukraintseva 1998).

Survival at adult and old ages. Adult and old-age survival rates also have been substantially increasing, particularly since 1950 (Vaupel et al. 1998) owing to new successful treatments of adult diseases with high fatality rates in the past (e.g., myocardial infarct, stroke, hepatitis, pancreatitis, tuberculosis, diabetes, and gastric ulcer). The efficient management of infectious diseases common in the young as well as the old (e.g., the flu and diarrhea) has been contributing to rising adult survival rates, too. Many people who would have died from these diseases in the past survive the same conditions today. However, they probably remain more vulnerable to pathologies, including cancer, compared to those who would have survived in the past without treatment, as the following examples show.

How improved survival from infections could elevate cancer risk. Suppose there is a frail person, who is more vulnerable to infection than his or her peers because of an inherent insufficiency in the immune response, for instance. The person survives nevertheless a number of infections with the help of new antibiotics. However, he or she continues to be more susceptible to the infection because the original deficit in immunity still persists. This results in a higher probability of developing chronic inflammation. The chronic inflammation, in turn, is one 
of the major cancer risk factors (Pozharisski et al. 1979, Coussens and Werb 2002). An increase in the survival of people who are vulnerable to infections therefore increases the prevalence of chronic inflammatory conditions and thus may elevate cancer risks in a population.

Associated trends in disease morbidity linked to chronic inflammation provide support for this view. Chronic inflammation is a base not only for cancer but also for allergic disorders (e.g., asthma). Similar to cancer, the risk of asthma increased substantially in many countries during the past decades (Akinbami and Schoendorf 2002, Soriano et al. 2003). This increase, too, is linked to economic progress. Several studies indicate that vulnerability to asthma is correlated to cancer vulnerability. A meta-analysis performed by Santillan et al. (2003) revealed significant increases in cancer risks (about twice in average) unrelated to smoking among asthma patients. Our preliminary study of old individuals from National Long Term Care Survey (NLTCS), aged 65 and above in 1999, confirms this finding (Ukraintseva, Michalsky, and Yashin - unpublished data). We found an almost two-fold increase in cancer prevalence among females who reported asthma in the anamnesis. These results indicate that an increased proportion of individuals prone to chronic inflammation is an important factor in the rise cancer risks in developed countries.

\section{How improved survival from stroke or myocardial infarct could elevate cancer risk.}

Another example of dependent pathologies concerns an intriguing trade-off between vulnerability to cancer and stroke (as well as cancer and ischemic heart disease or myocardial infarct (MI)), which is based on inter-individual differences in the intensity of apoptosis in postmitotic cells (e.g., mature neurons and cardiomyocites). When an individual has a high susceptibility to apoptosis in his or her cells (e.g., due to low cellular resistance to environmental stress or an inherently higher activity of the apoptotic signal), then this individual has a higher risk of death in case of a stroke or MI, but a lower risk in the case of cancer. Why is this the case?

With strokes, the higher activity of the apoptotic signal means that a relatively high number of nerve cells will die from damage caused by ischemia, consequently leading to a higher number of destroyed areas and affected nerve connections in the brain as well as a higher probability of paralysis, dementia, and death from the stroke. A similar mechanism relates to ischemic heart disease or MI. With cancer, by contrast, the higher intensity of apoptosis will result in greater chances of surviving the disease due to the elevated susceptibility of cells to treatment (e.g., chemotherapy or radiation). 
In the opposite situation (i.e., a lower activity of the apoptotic signal), a greater number of neurons survive ischemia, so that the survival of stroke patients increases. However, the lower apoptotic activity would simultaneously mean better chances of cancer cell survival.

A number of studies confirmed that neurons die from apoptosis in oxygen-deprived brains and that the lower activity of the apoptotic signal leads to the better survival of neurons after stroke-induced ischemia (reviewed in Barinaga 1998). This finding suggests new approaches for the treatment of the consequences of stroke (as well as myocardial infarct). Preliminary results of several current trials (e.g., the treatment of acute stroke with DP-b99, an anti-apoptotic compound of D-Pharm company) are demonstrating that medicated suppression of apoptosis applied after the stroke improves the survival of the patients. The lowered level of apoptosis has shown to be associated with a higher resistance of tumor cells to anti-cancer therapy, leading to elevated mortality from cancer (Haffty and Glazer 2003). A large study of a cohort of 10,923 male coronary patients in Israel revealed a significantly increased total risk of cancer in men with coronary heart disease compared to the general population (Reicher-Reiss et al. 2001). This excess was mainly due to cancers of the lung, bladder, and colon - sites that are among the most prevalent today.

Thus, we assume that individuals who survived a stroke, heart disease, or MI could in part be more vulnerable to cancer (e.g., due to an innately lowered activity of the apoptosis) compared to their peers who died from these pathologies and were eliminated from the population. Increasing the number of such survivors favors an increase in the proportion of cancer-prone subjects in the population.

\section{Cancer incidence in countries with short and long histories of economic growth. Our} hypothesis about an increase in the proportion of individuals who are more vulnerable to cancer implies that countries with a short history of high economic development (20-30 years) manifest a lower overall cancer risk than countries with a long history of economic development, particularly at old ages. This is because old individuals in rapidly developing countries have been experiencing a high quality of life only since recently, whereas they faced more difficult living conditions earlier in their life. In such conditions, robust individuals are more likely to pass environmental selection and reach old age. This is possibly a reason for the lower proportion of individuals who are vulnerable to cancer among the elderly in recently developed countries compared to countries with long histories of economic growth. That is, overall cancer incidence rates should be lower with the former scenario. Figure 6 confirms this prediction. 
Figure 6 about here

The figure shows that age-specific cancer incidence rates in Japan, Singapore, and Kuwait (the "young" developed countries) are lower than in the United States, the United Kingdom, and Switzerland (the "old" developed countries) despite similar standards of cancer diagnostics across these countries.

Differences in cancer incidence among migrants. IARC data on migrants to Israel (IARC 1997) allows for a comparison of cancer risks in adult Jews who presently live in Israel but were born and grew up in other countries. Figure 7 shows different cancer incidence rates at the same age for groups of different origins.

Fig. 7 about here

One can see that Jews born in Africa (a less developed region) have lower risks of cancer than those born in Europe (a more developed region). The discrepancy is unlikely to be due to differences in cancer diagnostics because all people under study are citizens of the same country. This data support our view that environmental selection in less developed countries favors the survival of robust individuals who are less vulnerable to cancer.

Not sufficiently trained immune system. Another reason for the observed differences in cancer rates among migrants in Israel (Figurer 7 above) is that the immune system of the individuals that grew up in less developed regions is stronger than that of individuals from the more developed regions. This is because it is better "trained" by more frequent stimulation with antigens. Training the immunity may create a hormesis effect (i.e., where a toxic substance acts like a stimulant in small doses, and it may help to strengthen the organism in its fight against more harmful substances in the future). Indeed, children of the more developed countries are less exposed to negative environmental factors (e.g., drinking and bath water containing wide spectrum of bacteria). As a result, their immune system is not sufficiently stimulated to fight dangerous antigens that appear later in life. This enhances their chances of developing chronic inflammatory conditions.

Some researchers directly connect excessive disinfection and a lack in the stimulation (especially in early childhood) of the host immune system with infectious (e.g., microbial, viral, and parasitic) factors in westernized communities with the increased risk of chronic inflammatory diseases, including skin allergies and asthma (Kramer et al. 1999, Strannegard and 
Strannegard 1999, Fujita 2000, Lovik 2000, Imai and Fujita 2004). Chronic inflammation, in turn, may increase cancer risks in the way discussed above.

Thus, an increase in population vulnerability to cancer can be attributed not only to better living conditions that improve the survival of frail individuals, but also because these living conditions may increase vulnerability during the life of an individual.

\section{Summary of Section 4.2}

(1) The increased proportion of individuals suffering chronic inflammation is likely to contribute to higher cancer risks in more developed countries. Improvement in health standards "relax" environmental selection and favor the survival of frail people who have weakened immunity and are prone to develop the chronic inflammation. The latter is one of key cancer risk factors.

(2) Survivors of several common diseases with high fatality rates in the past (e.g., stroke and MI) may have a greater predisposition to cancer. One possible mechanism involves the trade-off in apoptotic response to cell damage between the individuals predisposed to cancer and stroke or MI. The increased proportion of stroke, heart disease, and MI survivors may have contributed to the higher cancer rates in more developed countries.

(3) Excessive disinfection and hygiene may reduce the adaptive capabilities of an organism.

Overprotection against environmental exposures results in a lack of training the immune system sufficiently to combat illness. This, in turn, elevates the chances of developing chronic inflammation, favoring an increase in cancer risks.

\subsection{How the Western Life-Style Increases Vulnerability to Cancer}

Many behavioral and dietary habits are common in economically prosperous countries but not typical of populations in less developed ones. These habits reflect the Western life-style. In this section, we discuss the Western pattern of food consumption and the number of contemporary medicines. They are not directly carcinogenic themselves, but they may increase vulnerability to cancer by, e.g., affecting the metabolic ways of processing internal carcinogens and/or favoring chronic inflammation in an organism.

\subsubsection{The Western Pattern of Food Consumption.}

The western pattern of food consumption is characterized by a high content of animal protein (from meat, eggs, and cheese), fat, and purified sugar, as well as a low content of crude plants and grains in the everyday diet. This pattern is typical of developed countries, but not of the 
developing ones. A number of studies suggest a causal connection between the spread of Western dietary habits and changes in the prevalence of cancer sites in a country.

Protein and fiber. It has been shown that individuals with relatively high meat consumption face up to twice the risk of colon cancer (Willett 1989, Kearney et al. 1995, Tiemersma et al. 2004) and a less consistent but nevertheless increased risk of male prostate cancer (LeMarchand et al. 1994, Giovannucci et al. 1993).

Kagawa et al. (1978) found that the traditional food consumption pattern in Japan in the past was characterized by a high proportion of crude grain (barley), and a low proportion of any kind of animal protein. Since the 1950s, this diet has been gradually replaced by one that includes a high proportion of protein and a low proportion of barley. Other components of the Japanese diet (e.g., vegetables) did not experience large changes during the same period. The colon cancer incidence rate has been increasing drastically in Japan since then, while the rate of stomach cancer has been decreasing slightly (Figure 8).

Figure 8 about here

Changes to Japanese food patterns may be partly responsible for these trends in colon and stomach cancers. Excessive crude fibers in food harms the stomach's mucous membrane and promotes inflammation, thus increasing the vulnerability to stomach cancer. Decreased fiber intake diminishes this harm and reduces stomach susceptibility to cancer. At the same time, it suppresses intestinal motility and may elevate the risks of colon cancer. This is because motility prevents the intestine from festering. Festering creates an environment conducive to the development of bacteria imbalance in the intestine. This imbalance, in turn, favors carcinogenic production by colon bacteria, e.g., E.coli (Kearney et al., 1995; Monson and Walsh 1996; Falk, 1998; Parsonnet, 1999). An increased intake of meat also promotes food festering in the intestine accompanied by bacteria imbalance and increasing internal carcinogenic exposure (Kearney et al., 1995; Parsonnet, 1999).

\subsubsection{New Medicines}

Some medicines and dietary supplements that are prevalent in developed but not in developing countries may increase the vulnerability of an organism to cancer, although they have not been established as carcinogens themselves. The following example describes a possible mechanism of such an influence. 
A well-studied chemical, benzpyrene, is a non-direct carcinogen. It needs to be metabolically processed in an organism before it becomes harmful. First, an oxidative enzyme (e.g., Cytochromes P450) decomposes benzpyrene into intermediate products of the metabolism. Several of these products (e.g., phenol) are already carcinogenic. Some other substances of the organism (e.g., glutathione) bind these carcinogenic products to deactivate them and take them out of the metabolism (see e.g., Napalkov et al. 1987). If there is an appropriate balance between Cytochromes P450 and glutathione in a cell, then the carcinogen is quickly deactivated without harming the organism. However, if the amount of glutathione is not in balance with the amount of Cytochromes P450, the carcinogen deactivation process is delayed or incomplete. As a result, carcinogenic metabolites accumulate in the organism and increase the risk of cancer.

This simple example shows that metabolic balance is an important factor in the resistance of an organism to a carcinogen. Uncontrolled intake of medicines and dietary supplements affects the synthesis and amount of many substances in the organism. This, in turn, may disturb the delicate balance of events and processes leading to the neutralization of established carcinogens and elevate an organism's vulnerability to cancer. A number of studies on the simultaneous exposure to carcinogens and non-carcinogenic drugs support the existence of such a mechanism.

Paracetamol. Paracetamol (Acetaminophen, Tylenol, Contac) is a non-prescription antipyretic, which has been used extensively in developed countries since 1946. The drug is not classifiable by IARC in its carcinogenicity to humans. However, animal experiments have shown that paracetamol enhances the incidence of renal adenomas induced by an established carcinogen, N-nitrosoethyl-N-hydroxyethylamine (IARC Monographs 1990). That is, paracetamol, being not harmful on its own, increases the susceptibility of an organism to the carcinogen.

Antibiotics. Some prevalent antibiotics that are thought to be non carcinogenic in humans may enhance individual susceptibility to established carcinogens. Chloramphenicol, an antibiotic widely used since the 1950 s, is an example. Its application increased the incidence of lymphomas induced by an established carcinogen in mice, while the drug in itself did not show a carcinogenic effect (IARC Monographs 1990). This mechanism, again, may affect the metabolism of the established carcinogen in an organism.

Trade-off effects of antibiotics on risks of separate cancers. Antibiotics may have different and sometimes opposite effects on the risks of separate cancers. Earlier, we have discussed the role that new food consumption patterns play in prompting changes in the 
incidence rates of colon and stomach cancers in Japan. The introduction of new medicines is likely to make a contribution to the divergence between the trends in the incidence rates of these cancers as well. The parallel increase in colon cancer and the decrease in stomach cancer can be explained not only by changes in the food patterns, but also by the population-wide exposure to new prevalent antibiotics.

(1)Antibiotics and stomach cancer. A number of studies discussed in the IARC monographs (1994) established an association between seropositivity for the $H$. pylori bacteria and stomach cancer. An estimate of the relative risk was about four times the natural risk of this cancer. A possible mechanism involves the cancer promoting effects of chronic inflammation accompanying the infection. The prevalence of $H$. pylori infection is substantially lower in developed countries than in developing ones. In both, the prevalence is higher in the lower socioeconomic classes. A progressive reduction in the rate of this infection in successive birth cohorts of the developed countries (IARC Monographs 1994) is held to be the result of improved hygiene and the spread of antibiotics (e.g., metronidazole) which can destroy H. pliory bacteria. Antibiotic treatment may therefore decrease the risks of stomach cancer.

(2) Antibiotics and colon cancer. Many antibiotics are known to suppress normal intestinal flora, thereby promoting bacterial imbalance in the colon. As mentioned above, this imbalance often results in the suppression of the bifido-bacteria and promotion of the E.coli bacteria (Falk et al. 1998). The latter have a propensity to transform normal metabolic products (e.g., bile acids) into internal carcinogens, thereby increasing the risk of colon cancer (Parsonnet, 1999). Antibiotics may also influence the metabolism of external carcinogens. Metronidazole, an antibiotic which can destroy $H$. pilory and decrease the risk of stomach cancer, increased the incidence of colon cancer induced in rats by the administration of an established carcinogen (Sloan et al. 1983, IARC Monographs 1987).

Thus, antibiotics can influence the carcinogenic metabolism and inflammatory processes in an organism, increase the organism's vulnerability to some cancers and decrease its vulnerability to others.

Menopausal/postmenopausal estrogens. Menopausal and early postmenopausal estrogen therapy is common in developed countries, while still rare in developing countries. This could in part be responsible for the variation in incidence rates of female hormone-dependent cancers among these two groups of countries (IARC Monographs 1999). Postmenopausal estrogen therapy has been shown to substantially increase the risk of female endometrial cancer. At the same time, the therapy is associated with reduced risks of colon and cervical cancers (IARC 
Monographs 1999). It is also protective against osteoporosis. The risk of breast cancer was not reliably shown to rise under postmenopausal estrogen therapy. Among the original articles, risk estimates ranged from that which is considered protective to that which has an adverse effect in women who ever used estrogens, and no consistent quantitative effects of estrogens on breast cancer risk were found (Henrich 1992). In some studies, the risk increased only slightly or insignificantly after a period of five years or more (IARC Monographs 1999). In general, the findings do not support increased risks of breast cancer in women who took postmenopausal estrogens; however, premenopausal women who used estrogens have an increased risk of breast cancer of about 30 percent after fifteen years of exposure (Steinberg et al. 1991).

Thus, the recent increase in the risk of breast cancer, observed primarily at ages over 65, can be related to the long-term effects of premenopausal exposure to estrogens (e.g., as contraceptives) rather than to the short-term effects of postmenopausal therapy.

We do not consider here the widely-discussed results of two large Women's Health Initiative (WHI) Postmenopausal Hormone Therapy Trials (the first with estrogen plus progestin, and the second with estrogen alone). These trials have recently been concluded because of harmful effects of the therapy on risks of stroke and some other health disorders. However, a majority of women in these studies were aged 65 and above at the start of exposure to the hormone replacement therapy (HRT). HRT at this late age is still not common in developed countries. This therapy is often applied as symptomatic treatment of menopausal symptoms at ages 48-55 (around climacteric), and rarely later, because relevant symptoms tend to cease spontaneously by age 60 (Gosden 1985). Therefore, it makes little sense to discuss the results of the WHI studies, when explaining worldwide increases in cancer risks during several past decades.

Oral contraceptives combined. Another female hormonal treatment, oral contraception for pregnancy prevention, is more prevalent than postmenopausal therapy. Oral contraceptives usually include both estrogen and progesterone. This treatment has been popular in developed countries since the 1960s. Today, about 90 million women worldwide use 'the Pill' for contraceptive purposes. It has protective effects against endometrial and ovary cancers in women, but has been shown to increase the risk of liver cancer. The protective effect against endometrial cancer is mostly related to progesterone, not estrogen action (IARC Monographs 1999). Starting in the 1970s, the decline in female endometrial and ovarian cancer incidence rates, as well as the increase in the incidence rate of liver cancer in the United States, may 
therefore in part be due to the widespread exposure of American women to combined hormonal contraceptives.

The effect on the female organism of estrogen alone as well as in combination with contraceptives is very complex and depends on age (stage of ontogenesis) and tissue. Cancer promoting properties can be related to the estradiol-associated stimulation of growth hormones release (Veldhuis et al. 2004) and excessive cell proliferation, while cancer protective properties may be associated with increased regenerative potential and competitive abilities of normal host cells surrounding a transformed cell or latent tumor (Ukraintseva and Yashin 2003, 2004).

\subsubsection{Chemicals Used at Home}

Chemicals used at home are tested for carcinogenic properties before market introduction: They therefore are unlikely to be carcinogenic or mutagenic themselves. However, pre-market testing of chemicals usually does not take into account that these products may occasionally be consumed with drink or food, because they are intended for use outside the organism only. The problem is that the clearance of surfaces (e.g., glasses and plates) from such chemicals is often poor (particularly in small private food services), and their residual on the surfaces (e.g., on wineglasses) may go to the organism, accumulate and finally be sufficient to harm the organism. Unfortunately, there are very limited studies on this important topic (e.g., Travier et al. 2002) and no definite conclusion can be drawn to date.

\section{4 Factors of Economic Progress that Increase both Longevity and Vulnerability to}

\section{Cancer}

\section{4. 1 Cancer and Aging: A Trade-Off?}

A paradox feature of economic progress is the parallel increase in life expectancy and cancer morbidity. Can these increases be causally linked? Some factors associated with high economic development and a Western life-style (e.g., food enriched with growth factors and postponed childbirth) influence the parameters of organism's aging and development (e.g., the length of growing and reproductive periods, the rate of growth, the height and weight), so that it could result in a postponement of aging manifestation in individuals. These same factors may enhance organism's susceptibility to cancer (e.g., because of protracted exposure to inner cancer risk factors, such as growth hormones). That is, there are factors that may favor an increase in both longevity and cancer risks in populations of developed countries. Below, we discuss the evidence available on the possibility of such a scenario. 


\section{4. 2 Exposure to Growth Factors}

Growth factors in cancer. Excess of internal growth factors is considered to play an important role in cancer development and is associated with increased risk of developing several common cancers (Giovannucci 1995, Pelengaris 2002, Pollak et al. 2004). The mechanism involves a higher cell proliferation rate favoring malignant transformation, the anti-apoptotic effects of growth factors, and increasing rates of latent tumor growth in individuals with higher levels of internal growth factors (e.g., IGF1) (Pollak et al. 2004).

Growth factors in aging. As for aging and longevity, there are limited data on increasing life span due to excessive growth factors or stimulating respective signaling pathways in cells. It has been demonstrated that the overexpression of a growth factor receptor (tyrosine kinase receptor, tkr-1) improved survival (by an average of 65 percent) and stress resistance in nematodes (Murakami and Johnson 1998). Ruiz-Torres and Soares de Melo Kirzner (2002) showed on a sample of 205 healthy individuals aged 19-93 that old males with IGF-1 levels, similar to young ones, did neither have an age-dependent decrease in serum testosterone and lean body mass nor an increase in fat body mass. That is, they were biologically younger than their peers.

There is also non-direct evidence as to humans. It has been shown that the long-term use of estrogens significantly improves overall female survival at old ages (regardless of separate morbid risks). The relative risk of death from all causes varied between 0.5-0.7 (Bush et al. 1983, Petitti et al. 1987, Criqui et al. 1988, Henderson 1991, Ettinger et al. 1996, Cauley et al. 1997, Jansen et al. 2002). Other studies suggest that one of the primary effects that estrogens have is that they stimulate growth hormone $(\mathrm{GH})$ release. The effect of estrogens on survival is possibly due in part to the GH effect.

The mechanism of influencing growth factors on cancer and aging involves apoptosis. Data indicates that internal growth factors play a role in cell survival and tissue regeneration by inhibiting apoptosis (Wood and van der Kraak 2002, Fischer-Posovszky et al. 2004). As for cancer, growth factors contribute to tumor growth through the inhibition of apoptosis (Harris et al. 2002). Thus, one can suggest a connection between prolonged exposures to growth factors and increased both cancer risks and longevity.

Height. New generations become taller, and the proportion of tall individuals increases over time in more developed countries. Tallness and large body size are both associated with increased risks of breast cancer in postmenopausal women (Micozzi 1993, Stoll 1995, Hunter 
and Willett 1993). Taller people also appear to face higher risks of colon cancer (Miccozzi 1993, Monson and Wals 1996). An increase in height is usually attributed to enriched nutrition. The carcinogenic effect of height is attributed to greater and longer exposure of tall individuals to internal growth factors.

So far, the exact relation between height and longevity is not clear. Human populations show indeed an increase in both height and longevity. Species of larger size commonly live longer. However, shortness is often associated with longer life within the same animal species, e.g., mice (Bartke 2000). Additional studies are, therefore, needed.

Length of growth period. Prolonged exposure to internal growth factors increases the length of the growth period and postpones age at growth cessation. This, in turn, may lead to the postponement of aging manifesting in individuals.

Age at growth cessation and aging postponement. The organism may compensate deleterious age-associated changes better when it continues to grow than when it ceases growth. If the yield of newly appearing undamaged cells overrides that of old damaged cells, the organism has a higher ability to restore tissues and postpone aging. Differences between species in longevity are associated with differences in the length of the growth period. Interestingly, calorie restricted (CR) mice (which live longer and age slower) have shown a clear association between longevity and the length of the growth period. They increase weight over a longer period of time than $a d$ libitum fed mice, even though the former have lower weights at all ages (Sohal and Weindruch 1996). Unfortunately, there are few studies on the influence of age at growth cessation on human longevity because of obvious study limitations, e.g., the increment in height needs to be measured before ages 25-30, whereas differences in old age survival appear much later in life. It is difficult to find human data that contain longitudinal information from youth until oldest old ages. Note that the age at growth cessation does not automatically correspond to the age of sexual maturation (e.g., start of menarche in females). In human societies, the age of menarche has been decreasing with economic progress, while the age at growth cessation has been increasing in parallel, so that both growth and reproductive periods have been increasing in length.

Age at growth cessation and cancer risk. There are indirect indications on the role that age at growth cessation plays in cancer risks. A comparison of incidence rates for 26 cancer sites between first and second generation immigrants using native Swedes as a reference suggests that the first two decades of life are most important in setting the patterns of cancer development later in life (Hemminki $2002^{1,2}$ ). Cancers in first generation immigrants, who arrived in the country at 
ages 20 and over (i.e., at the end of the growth period) followed the rates in the countries of origin, while in the second generation they approached the rates witnessed in the host country. This means that the organism is more vulnerable to environmental carcinogens while it is growing and exposed to a higher amount of internal growth factors. The prolongation of the growth period (postponed age at growth cessation) may elevate cancer risks.

We thus hypothesize that there is a causal association between a longer growth period, cancer risk, and longevity. We are currently testing this complex relationship with available longitudinal human data sets. As mentioned, human data sets that are keeping individual information from youth until old age are rare. We therefore also use data from rodent life-term experiments to address this issue.

\section{4. 3 Length of Reproductive Period}

Age of menarche. Enriched nutrition and obesity lead to earlier maturation, which is manifest in a decreasing age of menarche. In England and the United States, this index declined from a mean age of 15 at the beginning of the $20^{\text {th }}$ century to a mean age of 13 in the 1960 s (Sandler et al. 1984, Poppelton and Brown 1966). In less developed regions, e.g., Ethiopia, Egypt, Nepal, Kyrgyzia, and Papua New Guinea, the median age of menarche varied from ages 14 to 18 in the 1970s (Pawson 1976, Tanner 1981). In West European and North American countries (which are more developed regions), it varied from 12.5 to 13.5 in the same period. The age of menarche has a remarkable association with socioeconomic class. Women from low social classes in Tunis, Iraq, Singapore, and Turkey reported a median age between 13 and 14, while their native counterparts from high social classes reported a median age between 12.4 and 13.6. Even in the $19^{\text {th }}$ century, the mean age of menarche was lower in the middle-class samples (about 14.5) compared to the working class samples (about 16) (Tanner 1981).

In a study of 3,993 breast cancer cases and 11,783 controls, the age at menarche was found to be a cancer risk factor among pre-menopausal and post-menopausal women. A delay of two years corresponded to a 10 percent reduction in breast cancer risk (CI 6-15 percent). That is, later menarche reduced the risk of developing this cancer (Hsieh et al. 1991).

The age of menopause. The median age of menopause has increased with economic progress and a Western life-style. This age varies from 44 to 49 in less developed regions (e.g., India, South Africa, and Papua New Guinea) to 50 to 52 in more developed regions (e.g., England, the United States, and the Netherlands) (McKinaly et al. 1972, MacMahon 1966, van Keep et al. 1979). 
Late menopause is associated with a decreased risk of death at old age (Snowdon et al. 1989). Women who were menopausal after age 53 had a significant reduction in mortality risk (with an odds ratio of 0.62) compared to women who experienced menopause before age 46 (Jansen et al. 2002). The decline in mortality was due in particular to a reduction in mortality arising from cardiovascular disease. A study of 9,450 postmenopausal women in the Netherlands confirms this finding (de Kleijn et al. 2002). It revealed that women aged 52 years or above at menopause had a significant reduction (18 percent) in cardiovascular mortality $(\mathrm{RR}=0.82)$ compared to those aged 44 years or less at menopause. Our preliminary study of aging, Danish Twins (LSADT), followed up 1995-2000, showed that a menopause age of 52 or over is associated with decreased chances of death from all causes in women older than 75 years $(\mathrm{RR}=0.83)$ compared to women who had menopause at the usual ages (49-51).

As for cancer, later menopause is associated with elevated risks of ovarian and endometrial cancers in postmenopausal women (de Graaff and Stolte 1978, Franceschi et al. 1991). The data used by the authors indicate that there is probably a trade-off between the positive and negative effects of internal estrogens on cause-specific mortality, so that the resulting effect on the overall survival is positive.

A mechanism that involves prolonged exposure to estrogens. An explanation of how a longer reproductive period increases cancer risk as well as old age survival focuses on longer exposure of the female organism to internal estrogens. A decrease in the age of menarche and a rise in the age at menopause result in the prolongation of the reproductive period and hence the duration of exposure to internal estrogens in females. In turn, prolonged exposure to estrogens may result in different (and even opposite) effects on cancer morbidity and old age survival.

On the one hand, long-term therapy with estrogens increases the risk of several cancers (Steinberg et al. 1991, IARC Monographs 1999). On the other, plenty of studies demonstrate that regular exposure to estrogens significantly improves female survival at old ages (Bush at al. 1983, Petitti et al. 1987, Henderson 1991, Ettinger et al. 1996, Cauley et al. 1997, Jansen et al. 2002). Studies of hormonal treatment in women with menopausal symptoms (to cushion the deleterious effects of the climacteric) revealed that the treatment produces physiological antiaging effects and decreases the risk of age-related dementia (Yaffe et al.1998, LeBlanc et al. 2001, Resnick and Henderson 2002, Henderson 2004). Conjugated estrogens promote neuronal survival as well as reverse skin aging in pre-climacteric women. Ashcroft and colleagues (1999) found that delays in wound healing (which is an important aging biomarker) in the elderly is significantly diminished by topical estrogen in male and female patients. 
Thus, there is probably a trade-off between cancer and longevity, influenced by age at menopause and exposure duration to endogenous estrogens. The trade-off may be in part due to the favorable action of pre-menopausal estrogens on the consequent risks of cardiovascular diseases (CVD). Indeed, the total survival largely depends on mortality from CVD and cancer. The fact that later menopause is associated with improved total survival implies that its protective potential against CVD is substantial.

Giving birth at late age. Morabia and Costanza (1998) showed that age at first childbirth has increased in developed countries. Later age at first childbirth and null parity show some positive association with survival at old ages. Our preliminary study of aging Danish Twins (LSADT 1995-2000) revealed that an age of 40-43 at last childbirth is associated (although not significantly) with decreased chances of death in women older than 75 ( $R R=0.83)$ compared to women who had their last child before age 40 . In animal studies, selection for late reproductive ability also resulted in an increased life span of flies (Rose and Charlesworth 1981).

At the same time, late age at childbirth is associated with elevated risks of several human cancers, in particular of the breast in mothers, childhood leukemia, and brain cancer in the newborn (Dupont and Page 1987, Wohlfahrt and Melbye 2001, Hemminki et al. 1999). The breast cancer risk rose significantly with age at first birth: Women who gave first birth after the age of 35 had a risk increase by 40 percent compared to mothers who experienced their first birth before the age of 20 (Ewertz et al. 1990, Dupont and Page 1987). A higher age of the father was associated with a rising susceptibility to an established carcinogen (N-nitrosomethylurea) in mice offspring (Anisimov and Gvardina 1995) and with an elevated risk of prostate cancer in human offspring (Zhang et al. 1999).

As an explanation of how late age at childbirth increases both cancer risks and longevity, a higher age at childbirth on the one hand is associated with an increase of genetic defects in progeny (e.g., chromosome aberrations). This may enhance the organism's susceptibility to malignant transformation (Vogel and Motulski 1997). On the other hand, giving birth late may postpone aging of the female reproductive function.

Summary. Data from human and animal studies suggest that several factors of economic progress affect the parameters of individual aging and development in ways that increase both longevity and vulnerability to cancer. Prolonged durations of growth and reproductive periods in an individual lead to the postponement of the subsequent stages of aging, which in turn increases the potential longevity of species. At the same time, these changes increase exposure duration to internal growth factors and sex hormones (e.g., estrogens) which contributes to increased 
vulnerability to certain hormone-related cancers. This complex relationship between aging, health, and longevity is a very challenging phenomenon. It is a warning against simplified approaches to extend longevity without taking into account possible trade-offs between aging and health at old ages. Several trade-offs between morbidity and mortality and their possible mechanisms were discussed by Ukraintseva (2000), and Ukraintseva and Yashin (2003).

\section{Concluding Remarks}

New insights and ideas concerning the mechanisms of cancer development in humans are generated from a comparative analysis of age patterns, time trends, and place differences in cancer incidence rates. The results of such an analysis, performed in this chapter, suggest that:

(1) Improved cancer diagnostics does not explain in full the observed (until recently) increase in the overall cancer risk.

(2) There is no convincing evidence that elevated exposure to carcinogens is the only factor responsible for elevated cancer rates in developed countries.

(3) Several factors associated with high economic development and a Western life-style favor an increase in the proportion of susceptible to cancer individuals. These factors include (but not limited to):

- increasing the share of individuals prone to chronic inflammation (linked to relaxation of environmental selection);

- $\quad$ nutrition enriched with growth factors;

- a higher parental age.

(4) There are factors that enhance susceptibility to cancer and, at the same time, postpone aging manifestation in individuals. That is, they could favor increases in both longevity and cancer incidence rate in a population.

(5) Factors of economic progress that are responsible for decreased risks of some cancers (e.g., of the stomach and cervix) first of all include the successful prophylactics and treatment of relevant chronic inflammatory conditions (e.g., gastritis and cervicitis).

(6) Integrating the results of genetic, epidemiological, and clinical studies is critical to understanding observed trends in cancer incidence rate. More work systematizing knowledge from different areas of cancer research is needed to develop adequate measures that will help to reduce the cost of cancer burden for human society. 


\section{Acknowledgements}

We are very thankful to Prof. J.W. Vaupel for the possibility to conduct this study at Max Planck Institute for Demographic Research, as well as for his valuable comments on the paper. We also thank S. Backer and R. Flibotte-Lüskow for their great help in preparing this manuscript.

\section{References}

Abelev G. I. (1997) What a Tumor Is. Sorosovsky Obrazovatelny Journal, \#10.

Akinbami LJ, Schoendorf KC. (2002) Trends in childhood asthma: prevalence, health care utilization, and mortality. Pediatrics, 110(2 Pt 1):315-22.

Anisimov VN, Gvardina OE. (1995) N-nitrosomethylurea-induced carcinogenesis in the progeny of male rats of different ages. Mutat Res, 316(3):139-45.

Ashcroft GS, Greenwell-Wild T, Horan MA, Wahl SM, Ferguson MW. (1999) Topical estrogen accelerates spontaneous wound healing in aged humans associated with an altered inflammatory response. Am J Pathol., 155(4):1137-46.

Barinaga M. (1998) Stroke-Damaged Neurons May Commit Cellular Suicide. Science, Vol 281, 5381: 1302-1303.

Bartke A (2000) Delayed aging in Ames dwarf mice. Relationships to endocrine function and body size. Results Probl Cell Differ, 29: 181-202.

Bast, R.C., Kufe, D.W., Pollock, R. E., Weichselbaum, R.R., Holland, J.F., Frei, E., editors. (2000) Holland \& Frei Cancer Medicine. 5th ed. Canada: BC Decer Inc.

Brenner H, Arndt V, Sturmer T, Stegmaier C, Ziegler H, and Dhom G. (2000) Individual and joint contribution of family history and $\mathrm{H}$. pilory infection to the risk of gastric carcinoma. Cancer, 88(2): 274-9.

Bush TL, Cowan LD, Barrett-Connor E, Criqui MH, Karon JM, Wallace RB, Tyroler HA, Rifkind BM. (1983) Estrogen use and all-cause mortality. Preliminary results from the Lipid Research Clinics Program Follow-Up Study. JAMA, 249(7):903-6.

Buters JT, Sakai S, Richter T, Pineau T, Alexander DL, Savas U, Doehmer J, Ward JM, Jefcoate CR, Gonzalez FJ. (1999) Cytochrome P450 CYP1B1 determines susceptibility to 7, 12dimethylbenz[a]anthracene-induced lymphomas. Proc Natl Acad Sci U S, 96(5):1977-82.

Cauley JA, Seeley DG, Browner WS, Ensrud K, Kuller LH, Lipschutz RC, Hulley SB. (1997) Estrogen replacement therapy and mortality among older women. The study of osteoporotic fractures. Arch Intern Med., 157(19):2181-7.

Cole P and B Rodu (1996) Declining cancer mortality in the United States. Cancer, 78:10, 20458. 
Coussens, L.M., Werb, Z. (2002) “Inflammation and cancer.” Nature, 420(6917): 860-7.

DeGraaff J., Stolte L.A. (1978) Age at menarche and menopause of uterine cancer patients. Eur J Obstet Gynecol Reprod Biol, 8, 4: 187-93.

Dinse GE . (1998) Unexplained increases in cancer incidence in the united states from 1975 to 1994: Possible Sentinel Health Indicators? SEER study.

Dupont WD, Page DL. (1987) Breast cancer risk associated with proliferative disease, age at first birth, and a family history of breast cancer. Am J Epidemiol, 125(5):769-79.

Ebbert JO, Yang P, Vachon CM, Vierkant RA, Cerhan JR, Folsom AR, Sellers TA. (2003) Lung cancer risk reduction after smoking cessation: observations from a prospective cohort of women. J Clin Oncol, 21(5):921-6.

EstEve J, Kricker A, Ferlay J, and Parkin DM (1993) Facts and figures of cancer in the European community. IARC WHO.

Ettinger B, Friedman GD, Bush T, Quesenberry CP Jr. (1996) Reduced mortality associated with long-term postmenopausal estrogen therapy. Obstet Gynecol, 87(1):6-12.

EUCAN: Cancer Incidence, Mortality and Prevalence in the European Union in 1996, version 3.1. Ferlay J, F Bray, Sankila R, Parkin DM. (1999) IARC Cancer Base No. 4. IARC Press:

Lyon. (a product of European Network of Cancer Registries)

Ewertz M, Duffy SW, Adami HO, Kvale G, Lund E, Meirik O, Mellemgaard A, Soini I, Tulinius H. (1990) Age at first birth, parity and risk of breast cancer: a meta-analysis of 8 studies from the Nordic countries. Int J Cancer, 46(4):597-603.

Falk PG, Hooper LV, Midtvedt T, and Gordon JI (1998) Creating and maintaining the gastrointestinal ecosystem: what we know and need to know from gnotobiology. Microbiol Mol Biol Rev, 62(4): 1157-70.

Fischer-Posovszky P, Tornqvist H, Debatin KM, Wabitsch M. (2004) Inhibition of deathreceptor mediated apoptosis in human adipocytes by the insulin-like growth factor I (IGF-I)/IGFI receptor autocrine circuit. Endocrinology, 145(4):1849-59.

Franceschi S, La Vecchia C, Booth M, Tzonou A, Negri E, Parazzini F, Trichopoulos D, Beral V. (1991) Pooled analysis of 3 European case-control studies of ovarian cancer: II. Age at menarche and at menopause. Int J Cancer, 19;49(1):57-60.

Fujita K. (2000) Why allergic diseases increased? The perils of being too fastidious. Journal of Germfree Life and Gnotobiology, 30 (1): 26-28.

Giard RW, Coebergh JW, Casparie-van Velsen IJ. (1998) A marked increase in the rate of diagnosed prostate cancer in the Netherlands during 1990-1996. Ned Tijdschr Geneeskd, 142(35):1958-62. [Article in Dutch]

Giovannucci E (1995) Insulin and colon cancer. Cancer Causes control, 6:164-79. 
GLOBOCAN 2000 (2001). Ferlay J, Bray F, Pisani P, Parkin DM, and Ferlay I: GLOBOCAN 2000: Cancer Incidence, Mortality and Prevalence Worldwide, version 1.0. IARC Cancer Base No.5 Lyon, France, IARC Press.

Gonzalez FJ. (2000) Genetic polymorphisms in metabolizing enzymes. Cancer detection and prevention, Vol 24, Suppl. S-104: 153.

Gosden, R.G. (1985) Biology of Menopause: The Causes and Consequences of Ovarian Ageing. London: Academic Press.

Hanahan D, Weinberg RA. (2000) The hallmarks of cancer. Cell, 100(1):57-70.

Haffty BG and PM Glazer (2003) Molecular markers in clinical radiation oncology. Oncogene, 22: 5915-5925.

Harris SR, Schoeffner DJ, Yoshiji H, Thorgeirsson UP. (2002) Tumor growth enhancing effects of vascular endothelial growth factor are associated with increased nitric oxide synthase activity and inhibition of apoptosis in human breast carcinoma xenografts. Cancer Lett, 179(1):95-101.

Health for all. (2000) WHO Data Base. WHO Regional Office for Europe.

Health in Russia. (2000), Russian, [1999 Statistics. Russian Ministry of Health publication].

Health US (1997-2001) Department of Health and Human Services (DHHS) Publications.

Henderson BE, Paganini-Hill A, Ross RK. (1991) Decreased mortality in users of estrogen replacement therapy. Arch Intern Med, 151(1): 75-8.

Henderson VW. (2004) Hormone therapy and Alzheimer's disease: benefit or harm?

Expert Opin Pharmacother, 5(2):389-406.

Henrich JB. (1992) The postmenopausal estrogen/breast cancer controversy. JAMA, 268 (14): 1900-2.

Hemminki K, Li X. (2002) Cancer risks in second-generation immigrants to Sweden. Int J Cancer, 99(2):229-37.

Hemminki K, Li X. (2002) Cancer risks in Nordic immigrants and their offspring in Sweden. Eur J Cancer, 38(18): 2428-34.

Hemminki K, Kyyronen P, Vaittinen P. (1999) Parental age as a risk factor of childhood leukemia and brain cancer in offspring. Epidemiology, 10(3):271-5.

Hirsch FR, Merrick DT, Franklin WA. (2002) Role of biomarkers for early detection of lung cancer and chemoprevention. Eur Respir J, 19(6):1151-8.

Hsieh CC, Trichopoulos D, Katsouyanni K, Yuasa S. (1990) Age at menarche, age at menopause, height and obesity as risk factors for breast cancer: associations and interactions in an international case-control study. Int J Cancer, 46(5):796-800. 
Hunter DJ and Willet WC (1993) Diet, body size and breast cancer. Epidemiol Rev, 15: 110-32.

IARC (The International Agency for Research on Cancer [France]). (1965-1997) Cancer Incidence in Five Continents. Volumes I-VII. IARC Sci. Publ. Lyon: IARC.

IARC (1997) Parkin, D.M., Whelan, S.L., Ferlay, J., Raymond, L., Young, J., editors. Cancer Incidence in Five Continents. Volume VII. IARC Sci. Publ. No.143.Lyon: IARC.

IARC Monographs (1972-2001). IARC Monographs on the Evaluation of Carcinogenic Risks to Humans Vol. 1 - 78, published during 1972-2001, Lyon: IARC Press.

Separate Volumes:

IARC Monographs on the Evaluation of Carcinogenic Risks to Humans Vol. 31, 1983 (Some

food additives and naturally occurring substances).

IARC Monographs on the Evaluation of Carcinogenic Risks to Humans Vol. 38, 1986 (Tobacco smoking).

IARC Monographs on the Evaluation of Carcinogenic Risks to Humans Vol. 35, Suppl. 7, 1987 (Coal, coal-tars, soots).

IARC Monographs on the Evaluation of Carcinogenic Risks to Humans Vol. 44, 1988 (Drinking alcohol).

IARC Monographs on the Evaluation of Carcinogenic Risks to Humans Vol. 45, 1989

(Occupational exposures in petroleum refining; crude oil and major petroleum fuels).

IARC Monographs on the Evaluation of Carcinogenic Risks to Humans Vol. 50, 1990 (Some

pharmaceutical drugs).

IARC Monographs on the Evaluation of Carcinogenic Risks to Humans Vol. 56, 1993 (Salted fish).

IARC Monographs on the Evaluation of Carcinogenic Risks to Humans Vol. 59, 1994a

(Hepatitis viruses).

IARC Monographs on the Evaluation of Carcinogenic Risks to Humans Vol. 61, (Schistosomes, Liver Flukes, and Helicobacter pylori) 1994b.

IARC Monographs on the Evaluation of Carcinogenic Risks to Humans Vol. 64 (Human Papillomaviruses) 1995a.

IARC Monographs on the Evaluation of Carcinogenic Risks to Humans Vol. 62, 1995b (Wood dust).

IARC Monographs on the Evaluation of Carcinogenic Risks to Humans Vol. 66, 1996 (Some pharmaceutical drugs).

IARC Monographs on the Evaluation of Carcinogenic Risks to Humans, Vol.72, 1999

(Hormonal contraception and postmenopausal hormonal therapy).

Imai S and K Fujita (2004) Molecules of parasites as immunomodulatory drugs. Curr Top Med Chem, 4(5):539-52.

Jansen SC, Temme EH, Schouten EG. (2002) Lifetime estrogen exposure versus age at menopause as mortality predictor. Maturitas, 43(2):105-12.

Kagawa Y. (1978) Impact of Westernisation on the Nutrition of Japanese: Changes in Physique, Cancer, Longevity and Centenarians. Prev Med, 7(2): 205-17. 
Kearney J, Giovannucci E, Rimm EB, et al. (1995) Diet, alcohol, and smoking and the occurrence of hyperplastic polyps of the colon and rectum (United States). Cancer Causes Control, 6: 45-56.

Khuder SA and AB Mutgi (2001) Effect of smoking cessation on major histologic types of lung cancer. Chest, 120(5):1577-83.

de Kleijn MJ, van der Schouw YT, Verbeek AL, Peeters PH, Banga JD, van der Graaf Y. (2002) Endogenous estrogen exposure and cardiovascular mortality risk in postmenopausal women. Am J Epidemiol. 155(4):339-45.

Kramer U, Heinrich J, Wjst M, Wichmann HE. (1999) Age of entry to day nursery and allergy in later childhood. Lancet, 353(9151):450-4.

Kozma L. (1998) Age-dependent variation of doubling times in malignant disorders: why are the doubling times of tumours in childhood shorter than in adulthood? Med Hypotheses, 50(5): 41922.

LeBlanc ES, Janowsky J, Chan BK, Nelson HD. (2001) Hormone replacement therapy and cognition: systematic review and meta-analysis. JAMA, 285(11):1489-99.

LeMarchand L, Kolonel LN, Wilkens LR, et al. (1994) Animal fat consumption and prostate cancer: a prospective study in Hawaii. Epidemiology, 5: 276-82.

Levi F., Lucchini F., Negri E., et al. (1999) Cancer Mortality in Europe. EurJCancer, 35:14771516 ,

Longnecker MP (1994) Alcoholic beverage consumption in relation to breast cancer: metaanalysis and review. Cancer Causes Control , 5: 73-82.

Lovik M. (2000), Norwegian, [Increased occurrence of allergy--is modern life style the cause?] Tidsskr Nor Laegeforen, 120(27):3287-91.

Lynn AG, Ries LAG, Wingo PA, Miller DS, Howe HL, Weir HK, Rosenberg HM, Vernon SW, Cronin K, and Edwards BK. (2000) The annual report to the nation on the status of cancer, 19731997, with a special section on colorectal cancer. Cancer, 88(10): 2398-2424,.

MacMahon B and J Worcester (1966) Age at menopause. United States, 1960-1962. Vital Health Stat 1, 11(19):1-20.

Maehara Y, Emi Y, Tomisaki S, Oshiro T, Kakeji Y, Ichiyoshi Y, Sugimachi K (1996) Age-related characteristics of gastric carcinoma in young and elderly patients. Cancer, 77(9):1774-80.

McKean-Cowdin R., Feigelson H. S., Ross R. K. et al. (2000) Declining Cancer Rates in the 1990s. J. Clin. Oncol. 18: 2258-2268.

McKee M, Bobak M, Rose R, Shkolnikov V, Chenet L, Leond D. (1998) Patterns of smoking in Russia. Tob Control, 7(1):22-6. 
McKinaly S, Jefferys M, and Thompson B. (1972) An investigation of the age at menopause. $J$ Biosoc Sci, 4(2):161-73.

Miccozzi MS (1993) Functional consequences from varying patterns of growth and maturation during adolescence. Horm Res, 39 (Suppl 3): 49-58.

Monson R and Wals J, editors (1996) Harvard report on cancer prevention: Causes of human cancer. Smoking. Cancer Causes \&Control, Vol.1, Suppl 1: S5-6.

Morabia A and MC Costanza. (1998) International variability in ages at menarche, first livebirth, and menopause. World Health Organization Collaborative Study of Neoplasia and Steroid Contraceptives. Am J Epidemiol. Dec 15;148(12):1195-205. Erratum in: Am J Epidemiol 1999 Sep 1;150(5): 546.

Morimoto T, Sasa M, Yamaguchi T, Harada K, Sagara Y. (1994) High detection rate of breast cancer by mass screening using mammography in Japan. Jpn J Cancer Res, 85(12):1193-5.

Murakami, S. and T. E. Johnson (1998) Life extension and stress resistance in Caenorhabditis elegans modulated by the tkr-1 gene. Cur Biol 8, 19, 1091-4

Napalkov NP, Knyazev PG, Anisimov VN, and Lichachev AY. (1987), Russian, [Modern Knowledge on Mechanism of Carcinogenesis.] VINITI Reviews, Moscow, pp.84.

Nolte E, Scholz R, Shkolnikov V, McKee M. (2002) The contribution of medical care to changing life expectancy in Germany and Poland. Social Science \& Medicine, 55: 1905-1921.

Oganov RG (1995), Russian, [Prophylactic medicine]. Medicine News, 9(12): 4-5.

Parsonnet J., editor (1999) Microbes and Malignancy. NY: Oxford Univ. Press.

Pawson IG (1976) Growth and development in high altitude populations: a review of Ethiopian, Peruvian, and Nepalese studies. Proc R Soc Lond B Biol Sci. 27, 194(1114): 83-98.

Peer PG, van Dijck JA, Hendriks JH, Holland R, and Verbeek AL. (1993) Age-dependent growth rate of primary breast cancer. Cancer, 71:11, 3547-51.

Pelengaris S, Khan M, Evan G. (2002) c-MYC: more than just a matter of life and death. Nat Rev Cancer, 2 (10):764-76.

Persson I, Yuen J, Bergkvist L, Schairer C. (1996) Cancer incidence and mortality in women receiving estrogen and estrogen-progestin replacement therapy - long-term follow-up of a Swedish cohort. Int J Cancer, 67(3):327-32.

Petitti DB, Perlman JA, Sidney S. (1987) Noncontraceptive estrogens and mortality: long-term follow-up of women in the Walnut Creek Study. Obstet Gynecol, 70(3 Pt 1):289-93.

Pollak MN, Schernhammer ES, Hankinson SE. (2004) Insulin-like growth factors and neoplasia. Nature reviews. Cancer, 4: 505-518. 
Poppleton PK and Brown PE: (1966) The secular trend in puberty: has stability been achieved? Br J Educ Psychol, 36(1): 95-100.

Pozharisski KM, Likhachev AJ, Klimashevski VF, and Shaposhnikov JD (1979)

Experimental intestinal cancer research with special reference to human pathology. $A d v$ Cancer Res 30: 165-237.

Reicher-Reiss H, Jonas M, Goldbourt U, Boyko V, Modan B. (2001) Selectively increased risk of cancer in men with coronary heart disease. Am J Cardiol, 87(4):459-62, A6.

Resnick SM and VW Henderson (2002) Hormone therapy and risk of Alzheimer disease: a critical time. JAMA, 288(17):2170-2

Ries LAG, Eisner MP, Kosary CL, Hankey BF, Miller BA, Clegg L, and Edwards BK, editors (2001) SEER Cancer Statistics Review, 1973-1998, National Cancer Institute. Bethesda, MD, http://seer.cancer.gov/Publications/CSR1973_1998/.

Ries LAG, Smith MA, Gurnry JG et al., editors (1999) Cancer Incidence and Survival among Children and Adolescents: United States SEER Program, 1975-1995. The National Cancer Institute (NCI) monograph., NIH pub. Bethesda, MD.

Rodriguez C, Patel AV, Calle EE, Jacob EJ, Thun MJ. (2001) Estrogen replacement therapy and ovarian cancer mortality in a large prospective study of US women. JAMA. 285(11):1460-5.

Rose MR, Charlesworth B. (1981) Genetics of life history in Drosophila melanogaster. II. Exploratory selection experiments. Genetics. 97(1):187-96.

Ross SH (1998) Cervical cancer prevention. Nurs Spectr (Wash D C) 23, 8 (6): 12-4; quiz 14, Mar.

Ruiz-Torres A, Soares de Melo Kirzner M. (2002) Ageing and longevity are related to growth hormone/insulin-like growth factor-1 secretion. Gerontology, Nov-Dec;48(6):401-7.

De Rooij MJ, Rampen FH, Schouten LJ, Neumann HA. (1996) Total skin examination during screening for malignant melanoma does not increase the detection rate. Br J Dermatol, 135(1):42-5.

Sandler DP, Wilcox AJ and Horney LF (1984) Age at menarche and subsequent reproductive events. Am J Epidemiol, 119(5): 765-74.

Santillan AA, Camargo CA Jr, Colditz GA. (2003) A meta-analysis of asthma and risk of lung cancer (United States). Cancer Causes Control. 14(4):327-34.

Semiglazov V, Moiseenko V, Chernomordikova M. (1989), Russian, [Growth kinetics of breast cancer] Vopr Onkol, 35(3):288-93.

Soriano JB, Kiri VA, Maier WC, Strachan D.(2003) Increasing prevalence of asthma in UK primary care during the 1990s. Int J Tuberc Lung Dis, 7(5): 415-21. 
Sloan D, Fleizer D, Richards G, Murray D, and Brown R (1983) Increased incidence of experimental colon cancer associated with long-term metronidazole therapy. Am. J. Surg., 145, 66-70.

Snowdon DA, Kane RL, Beeson WL, Burke GL, Sprafka JM, Potter J, Iso H, Jacobs DR Jr, Phillips RL. (1989) Is early natural menopause a biologic marker of health and aging? Am J Public Health, 79(6):709-14.

Sohal R and Weindruch R (1996) Oxidative stress, caloric restriction, and aging. Science, 273, 59-63.

Soussi T (2000) Antibodies in the sera of patients with various types of cancer: a review. Cancer Res, 1, 60(7): 1777-88.

Steinberg KK, Thacker SB, Smith SJ, Stroup DF, Zack MM, Flanders WD, Berkelman RL. (1991) A meta-analysis of the effect of estrogen replacement therapy on the risk of breast cancer. JAMA 265(15):1985-90.

Soriano JB, Kiri VA, Maier WC, Strachan D. (2003) Increasing prevalence of asthma in UK primary care during the 1990s. Int J Tuberc Lung Dis, 7(5):415-21

Stoll BA. (1995) Timing of weight gain in relation to breast cancer risk. Ann Oncol. 6(3):245-8.

Strannegard O, Strannegard IL. (1999), Swedish, [Why is the prevalence of allergy increasing? Changed microbial load is probably the cause] Lakartidningen, 96(40):4306-12.

Tanner JM (1981) Menarcheal age. Science, 6, 214(4521): 604- 606.

Thomas F, Renaud F, Benefice E, de Meeus T, and Guegan JF (2001) International variability of ages at menarche and menopause: patterns and main determinants. Hum Biol, 73(2):271-90.

Tiemersma EW, Voskuil DW, Bunschoten A, Hogendoorn EA, Witteman BJ, Nagengast FM, Glatt H, Kok FJ, Kampman E. (2004) Risk of colorectal adenomas in relation to meat consumption, meat preparation, and genetic susceptibility in a Dutch population. Cancer Causes Control, 15(3):225-36.

Tominaga S. (1999)Major avoidable risk factors of cancer. Cancer Lett 143, 1: S19-23.

Travier N, Gridley G, De Roos AJ, Plato N, Moradi T, Boffetta P. (2002) Cancer incidence of dry cleaning, laundry and ironing workers in Sweden. Scand J Work Environ Health, 28(5):3418 .

Trepka MJ, Heinrich J, and Wichmann HE (1996) The epidemiology of atopic diseases in Germany: East-West comparison. Rev Environ Health, 11(3): 119-31, Jul-Sep.

Ukraintseva SV (1998), Russian, [Evolution of morbidity in human history]. Clinical Gerontology, 4: 61-65.

Ukraintseva SV (2000) Why is the proportion of centenarians increasing today? Is it possible that some centenarians originate from a frail part of a generation? Advances in Gerontology, 5. 
Ukraintseva S.V and A.I.Yashin (2003) Individual aging and cancer risk: How are they related? Demo Research, 9-8: 163-196.

Ukraintseva SV, Yashin AI. (2004) Cancer as "Rejuvenescence". Ann NY Acad Sci, 1019: 200205.

Van Heemst D. (2003), on behalf of the Long Life Consortium (a collaboration between the groups of RGJ Westendorp, PE Slagboom and B. Zwaan). Variation in human p53 affects old age survival and cancer mortality. IABG 10 Congress, 19-23 September 2003, Cambridge, UK.

Van Keep PA, Brand PC, and Lehert P (1979) Factors affecting the age at menopause. J Biosoc Sci Suppl, (6):37-55.

Vaupel JW, Carey JR, Christensen K, Johnson TE, Yashin AI, Holm NV, Iachine IA, Kannisto V, Khazaeli AA, Liedo P, Longo VD, Zeng Y, Manton KG, Curtsinger JW. (1998)

Biodemographic trajectories of longevity. Science, 280: 855-860.

Veldhuis JD, Anderson SM, Patrie JT, Bowers CY. (2004) Estradiol supplementation in postmenopausal women doubles rebound-like release of growth hormone $(\mathrm{GH})$ triggered by sequential infusion and withdrawal of somatostatin: evidence that estrogen facilitates endogenous GH-releasing hormone drive. J Clin Endocrinol Metab, 89(1):121-7.

Vogel V and Motulsky G (1997) Human Genetics. Problems and Approaches, $3^{\text {rd }}$ ed. Springer pp. 240-252, Berlin.

Wakai K, Seki N, Tamakoshi A, Kondo T, Nishino Y, Ito Y, Suzuki K, Ozasa K, Watanabe Y, Ohno Y; JACC Study Group. Japan Collaborative Cohort Study. (2001) Decrease in risk of lung cancer death in males after smoking cessation by age at quitting: findings from the JACC study. Jpn J Cancer Res, 92(8):821-8.

Warner HR. (1999) Apoptosis: a two-edged sword in aging. Anticancer Res, 19(4B):2837-42.

Wermers G, Dasgurta J and Dubey D (1986) Stress, the immune system, and cancer. In: Cancer, Stress, and Death. Day S, editor, NY, Plenum Pub, Corp: 33-60.

Willett WC (1989) The search for the causes of breast and colon cancer. Nature, 338: 389-94.

Wohlfahrt J, Melbye M. (2001) Age at any birth is associated with breast cancer risk. Epidemiology, 12(1):68-73.

Wood AW, van der Kraak G. (2002) Inhibition of apoptosis in vitellogenic ovarian follicles of rainbow trout (Oncorhynchus mykiss) by salmon gonadotropin, epidermal growth factor, and 17beta-estradiol. Mol Reprod Dev, 61(4):511-8.

Yaffe K, Sawaya G, Lieberburg I, Grady D. (1998). Estrogen therapy in postmenopausal women: effects on cognitive function and dementia. JAMA. 279(9): 688-95.

Yashin A.I., Ukraintseva S.V., De Benedictis G., Anisimov V.N., Butov A.A., Arbeev K., Jdanov D.A., Boiko S.I., Begun A.Z., Bonafe M., Franceschi C. (2001) Have the oldest old 
adults ever been frail in the past? A hypothesis that explains modern trends in survival. Journal of Gerontology: Biological Sciences, 56:10, B432-B442.

Yatani, R., Shiraishi, T., Nakakuki, K., Kusano, I., Takanari, H., Hayashi, T., Stemmermann, GN. (1988) Trends in frequency of latent prostate carcinoma in Japan from 1965-1979 to 19821986. J Natl Cancer Inst, 80, 9: 683-7.

Zang, EA, Wynder, EL. (1996) Differences in lung cancer risk between men and women: Examination of the evidence. Journal of the National Cancer Institute 88(3-4):183-192.

Zhang Y, Kreger BE, Dorgan JF, Cupples LA, Myers RH, Splansky GL, Schatzkin A, Ellison RC. (1999) Parental age at child's birth and son's risk of prostate cancer. The Framingham Study. Am J Epidemiol, 150(11):1208-12.

Zigeuner RE, Lipsky K, Riedler I, Auprich M, Schips L, Salfellner M, Pummer K, Hubmer G. (2003) Did the rate of incidental prostate cancer change in the era of PSA testing? A retrospective study of 1127 patients. Urology, 62(3):451-5.

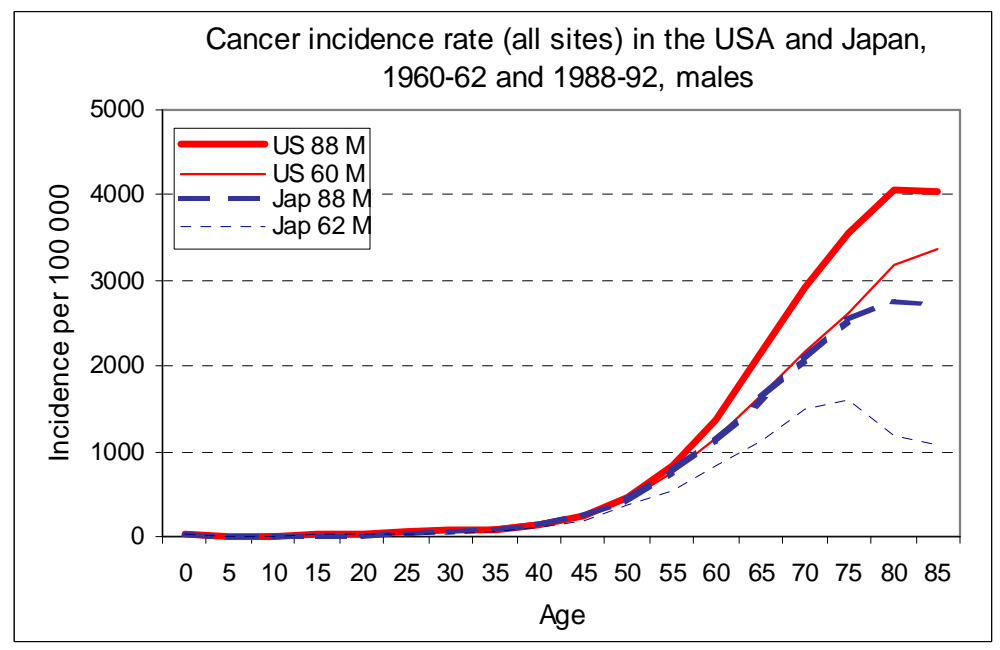

Fig. 1. Cancer incidence rate (average annual) in the USA (Connecticut), 1960-62 and 1988-92, and in Japan (Miyagi), 1962-64 and 1988-92 (IARC 1965-1997). 


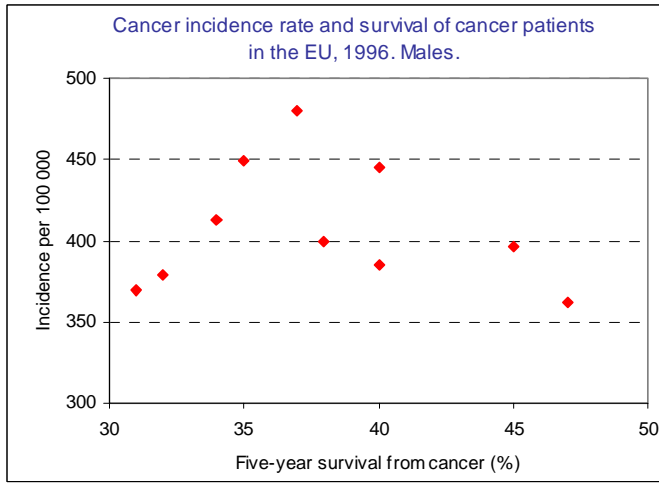

$\begin{array}{lcc}\text { Country } & \begin{array}{l}\text { 5-year } \\ \text { survival (\%) }\end{array} & \begin{array}{l}\text { Incidence per } \\ \text { 100 000 (ASR) }\end{array} \\ \text { United Kingdom } & 31 & 369.19 \\ \text { Denmark } & 32 & 379.08 \\ \text { Italy } & 34 & 412.45 \\ \text { Netherlands } & 35 & 448.87 \\ \text { France } & 37 & 480.4 \\ \text { Finland } & 38 & 399.41 \\ \text { Germany } & 40 & 445.01 \\ \text { Spain } & 40 & 384.86 \\ \text { Austria } & 45 & 396.72 \\ \text { Sweden } & 47 & 362.22\end{array}$

Fig. 2. Lack of a positive correlation between the age-standardized cancer incidence rate (ASR) and five-year survival from cancer in the countries of the EU (EUCAN 1999).

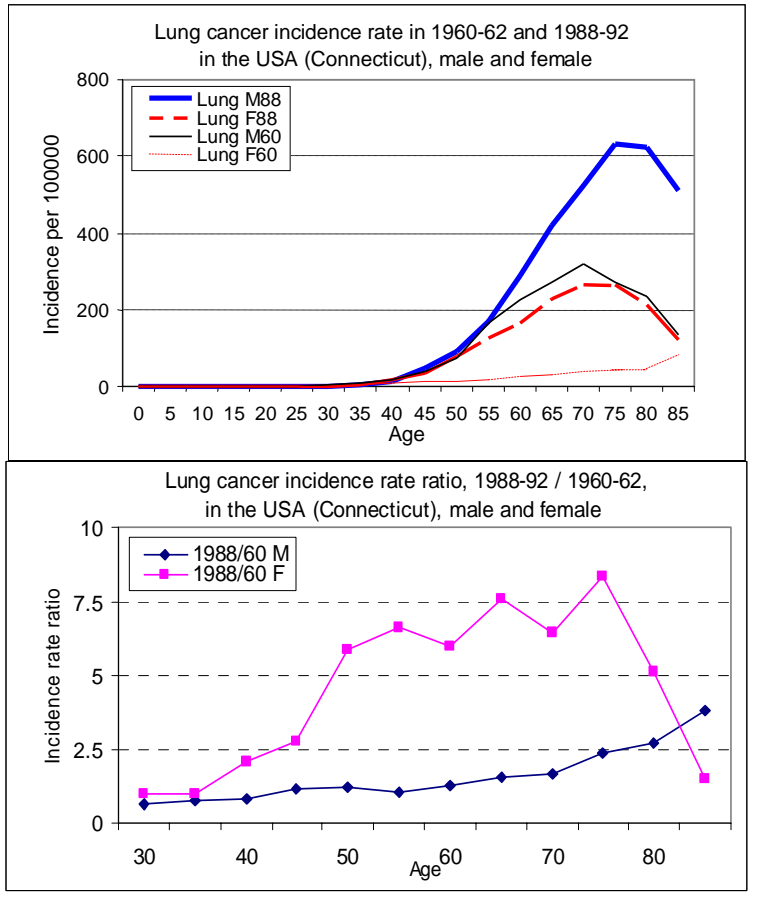

Fig. 3(1). Increase in the lung cancer incidence rate, 1960-62 and 198892, in Connecticut, by sex (IARC 1965-1997).

Fig. 3(2). Lung cancer incidence rate ratio of (1988-92) to (1960-62), in Connecticut, by sex (IARC 19651997). The rate has increased over time more rapidly in females than in males at all ages except the very old. 


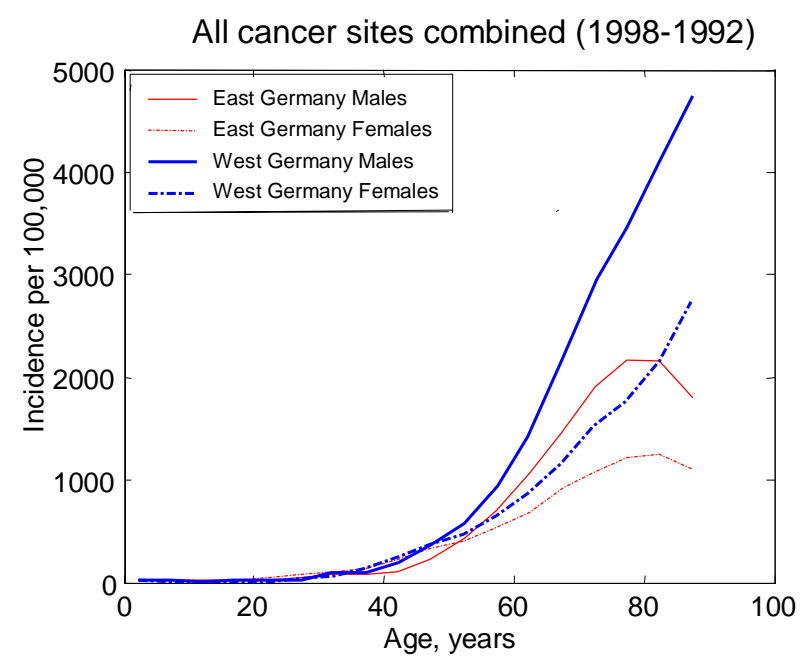

Fig. 4. Cancer incidence rate in East and West Germany, 1988-92, average annual (IARC 1997).

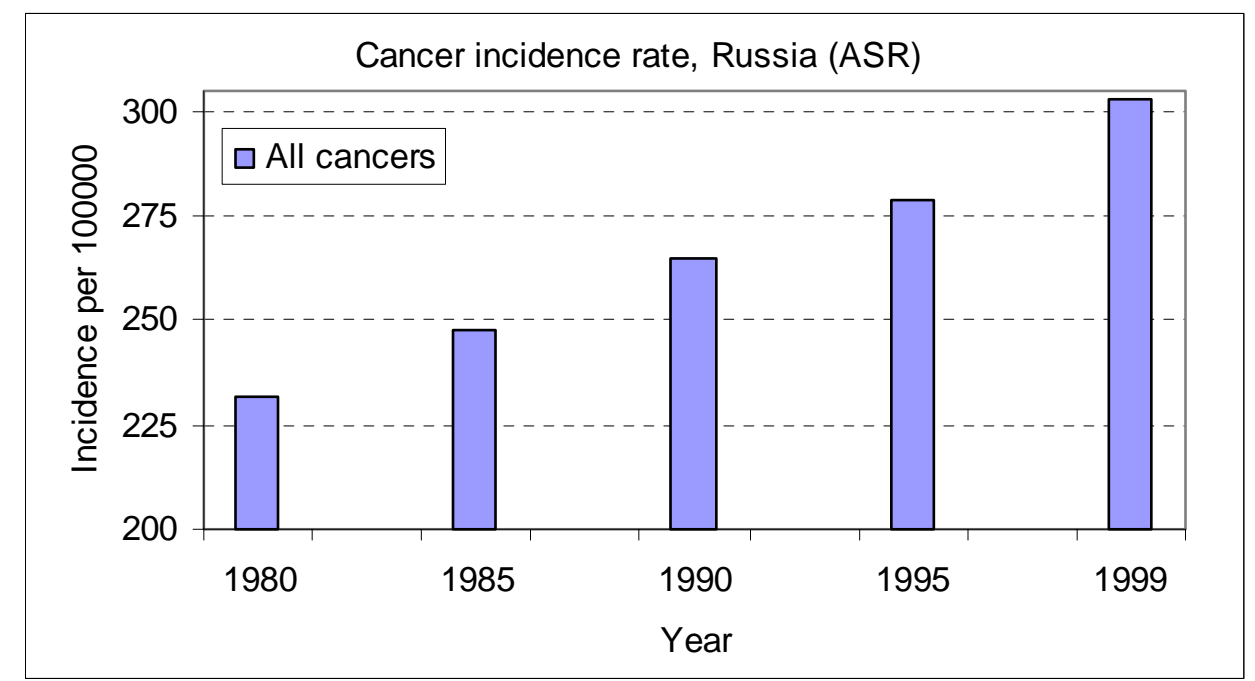

Fig. 5 (1). Steady increase in the age-standardised cancer incidence rate (for all sites combined) in Russia, 1980-1999 (Health in Russia 2000). 


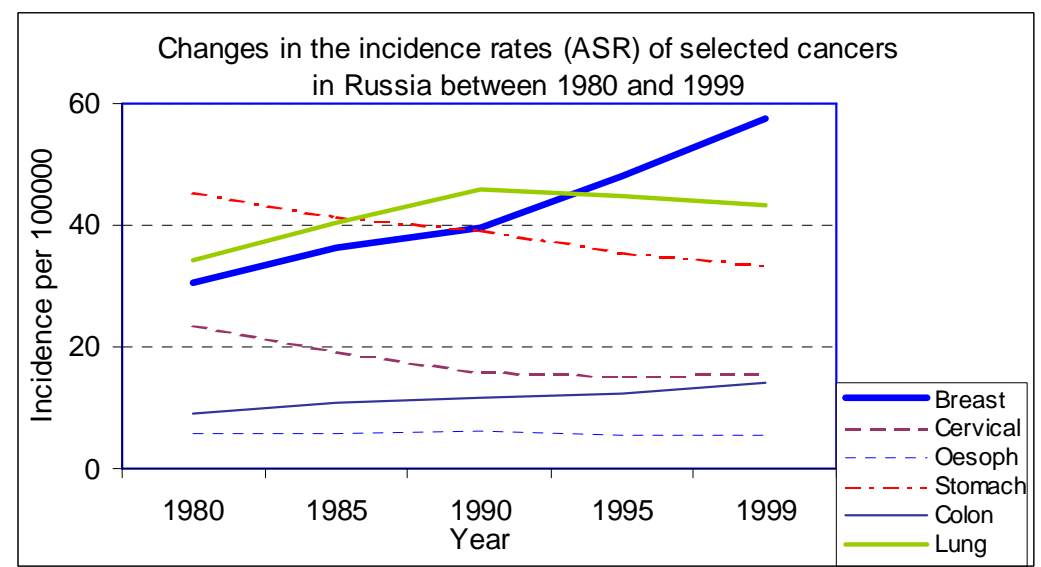

Fig. 5 (2). Age-standardized cancer incidence rates for selected cancers in Russia, 1980-1999 (Health in Russia 2000). One can see a slight decline for lung cancer rates beginning in the 1990s, a steady increase in the rate for colon cancer, an unchanged rate for oesophagus cancer, an increased rate for female breast cancer and a decreased rates for "infection-related" cancers (stomach and cervix).

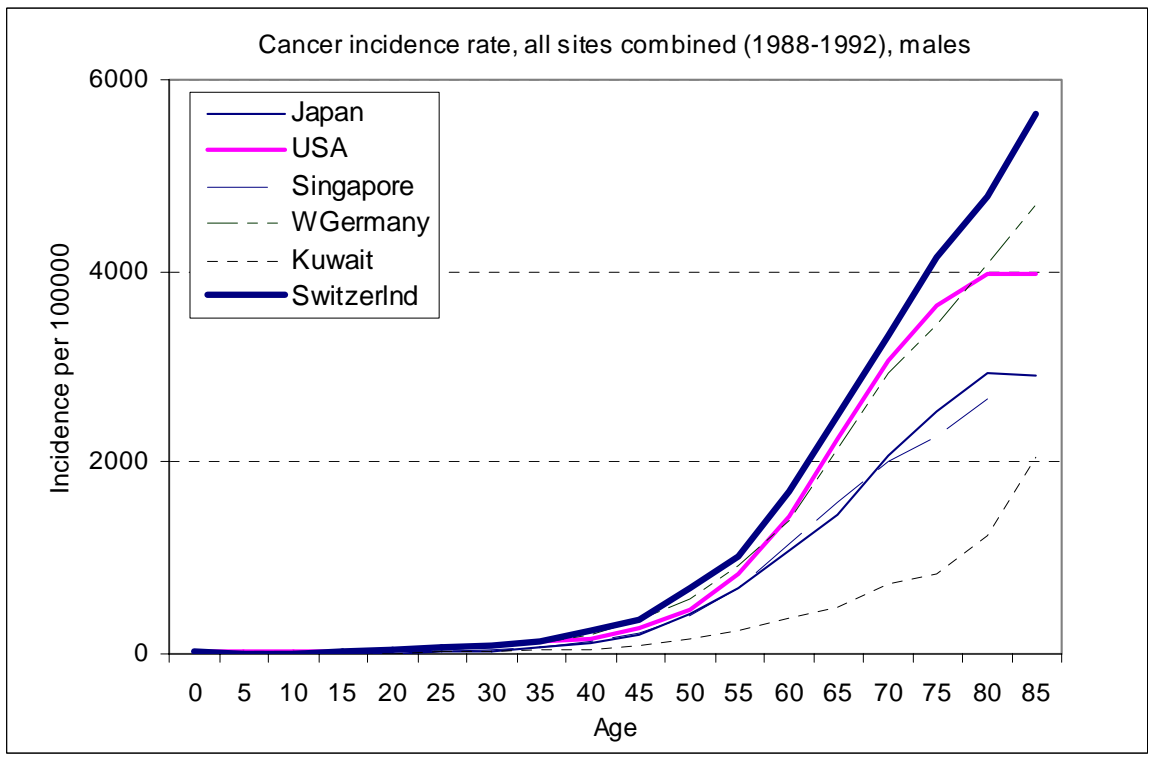

Fig. 6. Male cancer incidence rates in developed countries with different histories of economic development (IARC 1997). Countries with newly developed economies for the last 30 years (Japan, Singapore, and Kuwait) exhibited lowe cancer rates than countries with a long history of economic growth, such as the USA, Switzerland, and West Germany 


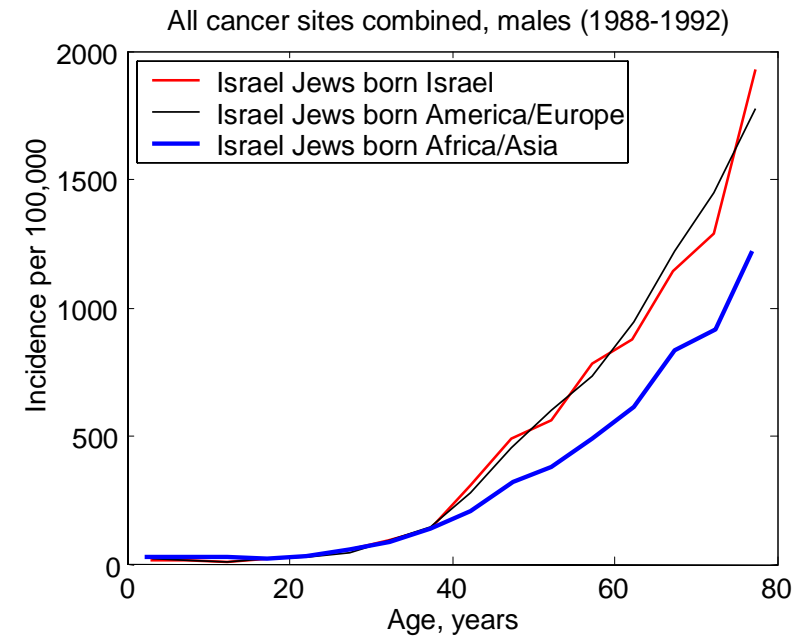

Fig. 7. Overall cancer incidence rate among Jews, who presently live in Israel, but were born outside the country (IARC 1997). Jews born in Africa/Asia exhibit a lower cancer incidence rate than Jews born in America/Europe or in Israel despite a similar quality of medical diagnostics available to all of them in Israel.

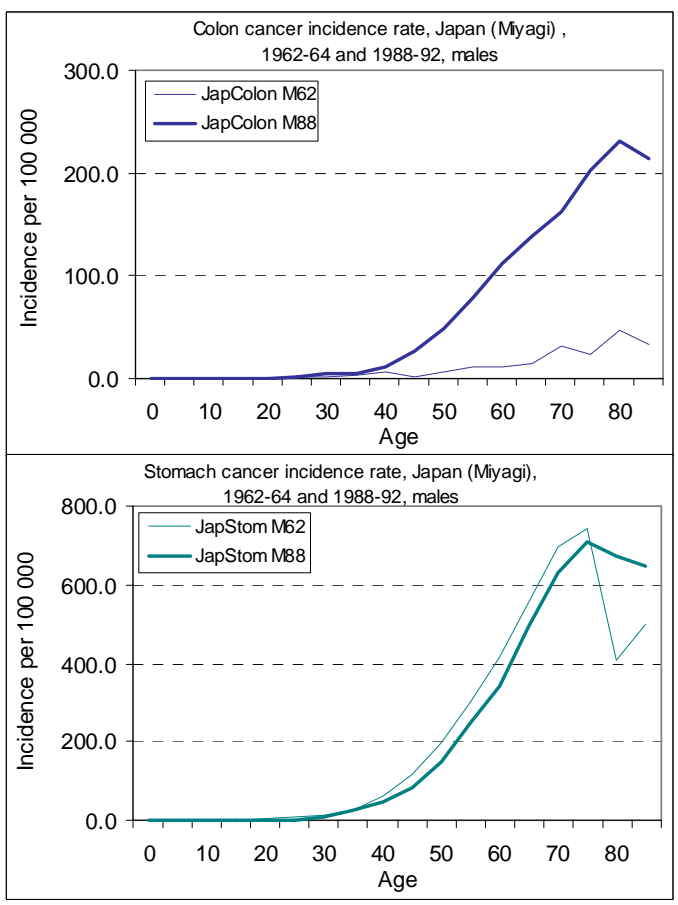

Fig. 8. Change in colon and stomach cancer incidence rates in Japan (Miyagi), 1962-64 and 1988-92 (IARC 1965-1997).

The male colon cancer risk drastically increased 1962-64 and 1988-92, while the stomach cancer risk slightly decreased (except old age) for the same period. 